\title{
Plastid genomics of Nicotiana (Solanaceae): insights into molecular evolution, positive selection and the origin of the maternal genome of Aztec tobacco (Nicotiana rustica)
} \footnotetext{
Waheed $^{1}$, Peter Poczai ${ }^{\text {Corresp., }}{ }^{\text {, Bushra Mirza }}{ }^{\text {Corresp. } 1}$

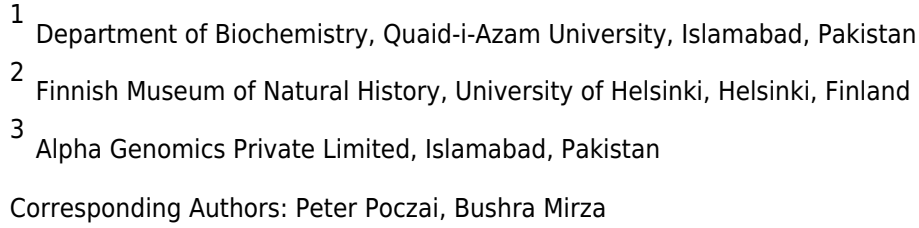

Furrukh Mehmood ${ }^{1,2}{ }^{2}$ Abdullah Abdullah ${ }^{1}$, Zartasha Ubaid ${ }^{1}$, Iram Shahzadi ${ }^{1}$, Ibrar Ahmed ${ }^{3}$, Mohammad Tahir

Species of the genus Nicotiana (Solanaceae), commonly referred to as tobacco plants, are often cultivated as non-food crops and garden ornamentals. In addition to the worldwide production of tobacco leaves, they are also used as evolutionary model systems due to their complex development history, tangled by polyploidy and hybridization. Here, we assembled the plastid genomes of five tobacco species: $N$. knightiana, N. rustica, $N$. paniculata, N. obtusifolia and N. glauca. De novo assembled tobacco plastid genomes had the typical quadripartite structure, consisting of a pair of inverted repeat (IR) regions (25,323-25,369 bp each) separated by a large single-copy (LSC) region $(86,510-86,716$ bp) and a small single-copy (SSC) region (18,441-18,555 bp). Comparative analyses of Nicotiana plastid genomes with currently available Solanaceae genome sequences showed similar GC content, gene content, codon usage, simple sequence repeats, oligonucleotide repeats, RNA editing sites, and substitutions. We identified 20 highly polymorphic regions, mostly belonging to intergenic spacer regions (IGS), which could be suitable for the development of robust and cost-effective markers for inferring the phylogeny of the genus Nicotiana and family Solanaceae. Our comparative plastid genome analysis revealed that the maternal parent of the tetraploid $N$. rustica was the common ancestor of $N$. paniculata and $N$. knightiana, and the later species is more closely related to N. rustica. Relaxed molecular clock analyses estimated the speciation event between $N$. rustica and $N$. knightiana appeared 0.56 Ma (HPD 0.65-0.46). Biogeographical analysis supported a south-to-north range expansion and diversification for $N$. rustica and related species, where N. undulata and N. paniculata evolved in North/Central Peru, while N. rustica developed in Southern Peru and separated from N. knightiana, which adapted to the Southern coastal climatic regimes. We further inspected selective pressure on protein- 
coding genes among tobacco species to determine if this adaptation process affected the evolution of plastid genes. These analyses indicate that four genes involved in different plastid functions, including DNA replication (rpoA) and photosynthesis (atpB, ndhD and $n d h F)$, came under positive selective pressure as a result of specific environmental conditions. Genetic mutations in these genes might have contributed to better survival and superior adaptations during the evolutionary history of tobacco species. 
2 Plastid genomics of Nicotiana (Solanaceae): insights into molecular evolution, positive selection and the origin of the maternal genome of Aztec tobacco (Nicotiana rustica)

4 Furrukh Mehmood ${ }^{1,2}$, Abdullah $^{1}$, Zartasha Ubaid ${ }^{1}$, Iram Shahzadi ${ }^{1}$, Ibrar Ahmed ${ }^{3}$, Mohammad 5 Tahir Waheed ${ }^{1}$, Péter Poczai*3, Bushra Mirza*1

$6{ }^{1}$ Department of Biochemistry, Quaid-i-Azam University, Islamabad, Pakistan

$7 \quad{ }^{2}$ Finnish Museum of Natural History (Botany Unit), University of Helsinki, Helsinki, Finland

$8 \quad{ }^{3}$ Alpha Genomics Private Limited, Islamabad, Pakistan

9 *Corresponding authors: Bushra Mirza (bushramirza@qau.edu.pk) 
27 Abstract

28 Species of the genus Nicotiana (Solanaceae), commonly referred to as tobacco plants, are often cultivated as non-food crops and garden ornamentals. In addition to the worldwide production of tobacco leaves, they are also used as evolutionary model systems due to their complex development history, tangled by polyploidy and hybridization. Here, we assembled the plastid genomes of five tobacco species: N. knightiana, N. rustica, N. paniculata, N. obtusifolia and N. glauca. De novo assembled tobacco plastid genomes had the typical quadripartite structure, consisting of a pair of inverted repeat (IR) regions (25,323-25,369 bp each) separated by a large single-copy (LSC) region (86,510 - 86,716 bp) and a small single-copy (SSC) region $(18,441$ 18,555 bp). Comparative analyses of Nicotiana plastid genomes with currently available Solanaceae genome sequences showed similar GC content, gene content, codon usage, simple sequence repeats, oligonucleotide repeats, RNA editing sites, and substitutions. We identified 20 highly polymorphic regions, mostly belonging to intergenic spacer regions (IGS), which could be suitable for the development of robust and cost-effective markers for inferring the phylogeny of the genus Nicotiana and family Solanaceae. Our comparative plastid genome analysis revealed that the maternal parent of the tetraploid N. rustica was the common ancestor of $N$. paniculata and $N$. knightiana, and the later species is more closely related to N. rustica. Relaxed molecular clock analyses estimated the speciation event between $N$. rustica and $N$. knightiana appeared $0.56 \mathrm{Ma}$ (HPD 0.65-0.46). Biogeographical analysis supported a south-to-north range expansion and diversification for $N$. rustica and related species, where $N$. undulata and N. paniculata evolved in North/Central Peru, while N. rustica developed in Southern Peru and separated from N. knightiana, which adapted to the Southern coastal climatic regimes. We further inspected selective pressure on protein-coding genes among tobacco species to determine if this adaptation process affected the evolution of plastid genes. These analyses indicate that four genes involved in different plastid functions, including DNA replication (rpoA) and photosynthesis $(a t p \mathrm{~B}, n d h \mathrm{D}$ and $n d h \mathrm{~F})$, came under positive selective pressure as a result of specific environmental conditions. Genetic mutations in these genes might have contributed to better survival and superior adaptations during the evolutionary history of tobacco species.

Keywords: Mutational hotspots, Nicotiana, plastid genomes, positive selection, substitutions, speciation 


\section{Introduction}

Nicotiana L. is the fifth largest genus in the megadiverse plant family Solanaceae, comprising 75 species (Olmstead et al., 2008; Olmstead \& Bohs, 2007), which were subdivided into three subgenera and fourteen sections by Goodspeed (1954). The subgenera of Nicotiana, as proposed by Goodspeed (1954), were not monophyletic (Aoki \& Ito, 2000; Chase et al., 2003), but most of Goodspeed's sections were natural groups. The formal classification of the genus has been refined to reflect the growing body of evidence that Nicotiana consists of 13 sections (Knapp, Chase \& Clarkson, 2004). One significant utilization of Nicotiana species has been as a source of genetic diversity for improving one of the most widely cultivated non-food crops, common tobacco $(N$. tabacum L.). This species is of major economic interest and is grown worldwide for its leaves used in the manufacture of cigars, cigarettes, pipe tobacco, and smokeless tobacco products consumed by more than one billion people globally (Lewis., 2011; Occhialini et al., 2016). While N. tabacum is the most notable commercial species for commerce, several additional species are also cultivated for smoking (N. rustica L.) and ornamental (N. sylvestris Spegazzini \& Comes) or industrial ( $N$. glauca Graham) purposes (Lester and Hawkes., 2001). Aztec or Indian tobacco (N. rustica), characterized by short yellowish flowers and round leaves, is widely cultivated in Mexico and North America. It was the first tobacco species introduced to Europe in the $16^{\text {th }}$ century, but later superseded by N. tabacum for its milder taste (Shaw, 1960). Known as "o-yen'-kwa hon'we" (real tobacco) by North American Iroquois (Kell, 1966), it was used for medicinal and ritual purposes or even in weather forecasting (Winter, 2001). Aztec tobacco is still cultivated in South America, Turkey, Russia and Vietnam due to its tolerance to adverse climatic conditions (Sierro et al., 2018).

Some members of Nicotiana offer several research advantages, including extensive phenotypic diversity, amenability to controlled hybridizations and ploidy manipulations, high fecundity, and excellent response to tissue culture (Lewis, 2011). Consequently, N. tabacum and N. benthamiana Domin have become model organisms in the generation of new knowledge related to hybridization, cytogenetics, and polyploid evolution (Goodin et al., 2008; Zhang et al., 2011; Bally et al., 2018; Schiavinato et al., 2019). The first complete plastid genome sequence to be published for N. tabacum (Shinozaki et al., 1986). Since then, the structure and composition of plastid genomes has become widely utilized in identifying unique genetic changes and the evolutionary 
87 relationships of various groups of plants. Furthermore, plastid genes have also been linked with 88 important crop traits such as yield and resistance to pests and pathogens (Jin \& Daniell, 2015).

89 Chloroplasts (cp) are large, double-membrane organelles with a genome size of 75-250 kb (Palmer, 1985). Most chloroplast encoded proteins are responsible for photosynthesis and for the synthesis of fatty acids and amino acids (Cooper, 2000). Angiosperm plastid genomes commonly contain 130 genes, comprised of up to 80 protein-coding, 30 transfer RNA (tRNA), and four ribosomal RNA (rRNA) genes (Daniell et al., 2016). The plastid genome exists in circular and linear forms (Oldenburg \& Bendich, 2015) and the percentage of each form varies within plant cells (Oldenburg \& Bendich, 2016). Circular- plastid genomes typically quadripartite structure, consisting of two inverted repeat regions (IRa and IRb), separated by one large single-copy (LSC) and one small single-copy (SSC) region (Palmer, 1985; Amiryousefi, Hyvönen \& Poczai, 2018a; Abdullah et al., 2019a). Numerous mutational events occur in plastid genomes, including variations in tandem repeats, insertions and deletions (indels), and point mutations; inversions and translocations are also common (Jheng et al., 2012; Xu et al., 2015; Abdullah et al., 2020).

The plastid genome of angiosperms has maternal inheritance (Daniell, 2007), which together with its conserved organization makes it extremely useful for exploring phylogenetic relationships at different taxonomic levels (Ravi et al., 2008). Plastid genome polymorphisms are useful for species barcoding, solving taxonomic issues, studying population genetics, and for investigating species adaptation to their natural habitats (Ahmed, 2014; Daniell et al., 2016; Nguyen et al., 2017). Genes in the plastid genome encode proteins and several types of RNA molecules, which play a vital role in functional plant metabolism, and can consequently undergo selective pressures. Most plastid protein-coding genes are under negative or purifying selection to maintain their function, while positive selection might act on some genes in response to environmental changes (Iram et al., 2019; Henriquez et al., 2020a).

Nicotiana species are diploid $(2 \mathrm{n}=2 \mathrm{x}=24)$, although allopolyploid species are also common in the genus (Leitch et al., 2008). Phylogenetic studies have shown that these allopolyploids were formed 0.4 million (N. rustica and N. tabacum) (Clarkson, Dodsworth \& Chase, 2017) to 5 million years ago (species of sect. Suaveolentes) (Schiavinato et al., 2020). Nicotiana tabacum $(2 n=4 x=48)$, is known to be a natural allopolyploid derived from two closely related ancestors (Lim et al., 2007). The paternal donor N. tomentosiformis L. $(2 \mathrm{n}=24)$ was confirmed by genomic 
117 in situ hybridization (GISH) (Clarkson et al., 2005), physical mapping (Bindler et al., 2011) and

118 genome sequencing (Sierro et al., 2014), while the maternal donor $N$. sylvestris $(2 \mathrm{n}=24)$ was 119 identified by plastid genome sequencing (Yukawa, Tsudzuki \& Sugiura, 2006). Aztec tobacco ( $N$. 120 rustica), like N. tabacum, is also an allotetraploid but has originated from the recent hybridization 121 of different parental species. Based on morphology, karyotype analyses and crossing experiments, 122 Goodspeed (1954) suggested the ancestral species are $N$. paniculata L. $(2 \mathrm{n}=2 \mathrm{x}=24$; maternal) and 123 N. undulata Ruiz \& Pav. $(2 \mathrm{n}=2 \mathrm{x}=24$; paternal). The identity of the parental species was 124 investigated using nuclear internal transcribed spacer (ITS) regions, chloroplast markers in situ 125 hybridization methods, and genome sequencing (Aoki \& Ito, 2000; Chese et al., 2003; Clarkson et 126 al., 2004; Lim et al., 2004, 2007; Kovarik et al., 2004; Sierro et al., 2018). These analyses 127 confirmed $N$. undulata as the paternal ancestor according to Goodspeed's hypothesis and showed 128 the genome of N. rustica lacks inter-genomic translocations (Lim et al., 2004, Kovarik et al., 2012), 129 while additivity can be observed in the 5S and 35S rDNA loci respect to its progenitors (Lim et 130 al., 2007), which were homogenized by concerted evolution (Kovarik et al., 2004). These analyses 131 did not provide further evidence for the maternal parent of $N$. rustica but suggested either $N$. 132 knightiana L. or $N$. paniculata L. could be the maternal donor.

133 Here, we assembled the plastid genome of five Nicotiana species and compared their sequences to 134 gain insight into the plastid genome structure of genus Nicotiana. We also inferred the phylogenetic relationship of the genus and investigated the selection pressures acting on proteincoding genes. We then identified mutational hotspots in the Nicotiana plastid that might be used for the development of robust and cost-effective markers in crop breeding or taxonomy. Lastly, we used this information to trace the origin of the maternal genome of the allopolyploid Nicotiana rustica.

\section{Materials and Methods}

\subsection{Plastid genome assembly and annotation}

Illumina sequence data of $N$. knightiana $(13.1 \mathrm{~Gb}$, accession number SRR8169719), N. rustica (15.5 Gb, SRR8173839), N. paniculata (35.1 Gb, SRR8173256), N. obtusifolia (23 Gb, SRR3592445) and N. glauca (12.5 Gb, SRR6320052) were downloaded from the Sequence Read Archive (SRA). The plastid genome sequence reads were selected by performing BWA-MEM mapping with default settings (Li \& Durbin, 2009) using Nicotiana tabacum (GenBank accession 
147 number: NC_001879) as a reference. Geneious R8.1 (Kearse et al., 2012) de novo assembler was

148 used to order the selected contigs for final assembly by selecting option "Medium sensitivity/Fast", 149 while keeping other parameters as default. Gene annotation was conducted using GeSeq (Tillich 150 et al., 2017) with a BLAT (Kent, 2002) search of $85 \%$ to annotate protein-coding genes, rRNAs 151 and tRNAs; CPGAVAS2 was used with default parameters by selecting option 1 "43-plastome" 152 (Shi et al., 2019). After automatic annotation, start/stop codons and the position of introns were 153 further confirmed manually by visual inspection of the translated protein of each gene in Geneious 154 R8.1 and BLAST search using default settings with homologous genes of plastid genomes of family Solanaceae. The tRNA genes were further verified by tRNAscan-SE version 2.0 with

156

157 158

159

160

161

162

163

164

165

166

167

168

169

170

171

172

173

174

175

176

default settings using options: sequence source "Organellar tRNA", search mode "Default", genetic code "Universal", and Cut-off score for reporting tRNAs "15" (Lowe \& Chan, 2016); ARAGORN version 1.2.38 was used with default parameters by selecting genetic code "Bacterial/Plant chloroplast" with maximum intron length of 3,000-bp (Laslett \& Canback, 2004). Circular genome maps were drawn with OGDRAW v1.3.1 (Greiner, Lehwark \& Bock, 2019) by uploading the GenBank (.gb) format of each plastid genome and selecting options: "Circular", "Plastid", "Tidy up annotation", and "Draw GC graph". The average coverage depth of Nicotiana species plastid genomes was calculated by mapping all raw reads without trimming to de novo assembled plastid genomes with BWA-MEM (Li \& Durbin, 2009) visualized in Tablet (Milne et al., 2009). Novel Nicotiana plastid genomes were deposited in NCBI (Table S1).

\subsection{Comparative genome analysis and RNA editing prediction}

Novel plastid genome sequences were compared through multiple alignments using MAFFT v7 (Katoh \& Standley, 2013). All parts of the genome, including intergenic spacer regions (IGS), introns, protein-coding genes, and ribosomal RNAs and tRNAs, were considered for comparison. Each part was extracted and used to determine nucleotide diversity in DnaSP v6 (Rozas et al., 2017). Substitution, transition and transversion rates compared to the $N$. tabacum reference using Geneious R8.1. Structural units of the plastid genome (LSC, SSC and IR) were individually aligned to determine the rate of substitutions and to further search for indels using DnaSP v6. Structural borders of plastid genomes were compared for 10 selected Nicotiana species using IRscope with option "GB file upload" and default settings (Amiryousefi, Hyvönen \& Poczai, 2018b). The online software PREP-cp (Putative RNA Editing Predictor of Chloroplast) was used 
177 with default settings to determine putative RNA editing sites (Mower, 2009) and codon usage and

178 amino acid frequencies were determined by Geneious R8.1.

179 2.3. Repeats analyses

180 Microsatellites within the plastid genomes of five Nicotiana species were identified using MISA 181 (Beier et al., 2017) with a minimal repeat number of 7 for mononucleotide repeats, 4 for 182 dinucleotide repeats and 3 for tri-, tetra-, penta- and hexanucleotide SSRs. We also used REPuter 183 software (Kurtz et al., 2001) with minimal repeat size set to $30 \mathrm{bp}$, Hamming distance set to 3 , 184 minimum similarity percentage of two repeat copies up to $90 \%$, and a maximum computed repeat 185 of $500 \mathrm{bp}$ for scanning and visualizing forward (F), reverse (R), palindromic (P) and 186 complementary (C) repeats. Tandem repeats were found with the tandem repeats finder using 187 default parameters (Benson, 1999).

\section{$188 \quad 2.4 . \quad$ Non-synonymous $\left(K_{a}\right)$ and synonymous $\left(K_{s}\right)$ substitution rate analysis}

189 To determined $\mathrm{K}_{\mathrm{a}}$ and $\mathrm{K}_{\mathrm{s}}$, protein-coding genes were extracted from the newly assembled 190 Nicotiana plastid genomes and aligned using MAFFT with the corresponding genes of the 191 previously published plastid genome of Nicotiana tabacum (Z00044.2) as a reference and analyzed using DnaSP v6. The data were interpreted in terms of purifying selection $\left(\mathrm{K}_{\mathrm{a}} / \mathrm{K}_{\mathrm{s}}<1\right)$, neutral evolution $\left(\mathrm{K}_{\mathrm{a}} / \mathrm{K}_{\mathrm{s}}=1\right)$, and positive selection $\left(\mathrm{K}_{\mathrm{a}} / \mathrm{K}_{\mathrm{s}}>1\right)$.

We evaluated the impact of positive selection using additional codon models to estimate the rates of synonymous and nonsynonymous substitution. The signs of positive selection were further

196

197

198

199

200

201

202

203

204

205 assessed using fast unconstrained Bayesian approximation (FUBAR) (Murrell et al., 2013) and the mixed effects model of evolution (MEME) (Murrell et al., 2012) as implemented in the DATAMONKEY web server (Delport et al., 2010). Sites with cut-off values of PP $>0.9$ in FUBAR were considered as candidates to have evolved under positive selection. From all the analyses performed in DATAMONKEY, the most suited model of evolution for each dataset was selected as directly estimated on this web server. In addition, the mixed effects model of evolution (MEME), a branch-site method incorporated in the DATAMONKEY server, was used to test for both pervasive and episodic diversifying selection. MEME applies models with variable $\omega$ across lineages at individual sites, restricting $\omega$ to $\leq 1$ in a proportion $p$ of branches and unrestricted at a proportion $(1-p)$ of branches per site. Positive selection was inferred with this method for $p$ values 
$206<0.05$ using the false discovery rate (FDR) correction according to Benjamini \& Hochberg (1995)

207 in Microsoft Excel.

\section{2.5. Phylogenetic analyses}

209 Plastid genome sequences of the genus Nicotiana were selected from the Organelle Genome

210 Resources of the NCBI (accessed on 21.02.2019) and used in phylogenetic inference along with

211 de novo assembled sequences of Nicotiana. The $\mathrm{x}=12$ clade includes the traditional subfamily

212 Solanoideae plus Nicotiana with the Australian endemic Anthocercideae tribe and takes its name

213 from the synapomorphy of chromosome numbers based on 12 pairs (Olmstead et al., 2008).

214 Nicotiana and Anthocercideae appear to be in a first branching position in the $\mathrm{x}=12$ clade, thus we

215 have chosen Solanum dulcamara L. (Amiryousefi, Hyvönen \& Poczai, 2018a) from the

216 Solanoideae tribe with a curated plastid genome as an outgroup for rooting our phylogenetic tree.

217 For the species included in our analysis, coding alignments were constructed from the excised

218 plastid genes using MACSE (Ranwez et al., 2011), including 75 protein-coding genes (Table S2).

219 For phylogenetic analysis, a 75,449-bp concatenated matrix was used with the best fitting

$220 \mathrm{GY}+\mathrm{F}+\mathrm{I}+\mathrm{G} 4$ model determined by ModelFinder (Kalyaanamoorthy et al., 2017) according to the

221 Akaike information criterion (AIC), and Bayesian information criterion (BIC). Maximum

222 likelihood (ML) analyses were performed with IQ-TREE (Nguyen et al., 2015) using the ultrafast

223 bootstrap approximation (UFBoot; Hoang et al., 2018) with 1,000 replicates. The key idea behind

224 UFBoot is to keep trees encountered during the ML-tree search for the original sequence alignment

225 and to use them to evaluate the tree likelihoods for the bootstrap sequence alignment. UFBoot

226 provides relatively unbiased bootstrap estimates under mild model misspecifications and reduces

227 computing time while achieving more unbiased branch supports than with standard bootstrap

228 (Hoang et al., 2018). TreeDyn was used for further enhancement of the phylogenetic tree analysis

229 (Dereeper et al., 2008; Lemoine et al., 2019).

230 Relative divergence times were estimated for species $N$. rustica and putative parental species using

231 BEAST v.1.8.4 (Drummond et al., 2012), applying GTR + I + G rate substitution to the protein-

232 coding plastid gene matrix. A Yule speciation tree prior and a uncorrelated relaxed clock model

233 that allows rates to vary independently along branches (Drummond et al., 2006) were used, with

234 all other parameters set to default. The median time split between the S. dulcamara and N. undulata

235 (mean $=25 \mathrm{Myr}$; standard deviation $=0.5)$ was used as a temporal constraint to calibrate the 
236 BEAST analyses derived from the Solanaceae-wide phylogeny of Särkinen et al. (2013).

237 Uncertainty regarding these dates was incorporated by assigning normal prior distributions to the

238 two calibration points (Couvreur et al., 2008; Evans et al., 2014). Four independent BEAST runs

239 were conducted with Markov Chain Monte Carlo (MCMC) samples based on 10 million

240 generations, sampling every 10,000 generations. Convergence of all parameters was assessed in

241 Tracer 1.5 (Rambaut et al., 2014) and 10\% of each chain was removed as burn-in. The Markov

242 chains were combined in LogCombiner 1.7.2. (Drummond et al., 2012) to calculate the maximum

243 clade credibility tree.

244 We defined six biogeographical areas based on the Köppen-Geiger climate classification and 245 further biogeographic evidence and distributions: (A) Colombian/Ecuadorian mountain range 246 mixed equatorial (Af), monsoon (Am), and temperate oceanic climate (Cfb); (B) Northern

247 Peruvian mountain range with tropical savanna climate (Aw); (C) Central Peru with equatorial 248 climate (Af); (D) Coastal Peru with cold semi-arid and desert climate (Bsk, BWk); (E) Peruvian 249 Mountain range with humid subtropical/oceanic highland climate (Cwb); and (F) Bolivian/Chilean 250 alpine/mountain range with mixed semi-arid cold (Bsk, BWk) and humid subtropical climate 251 (Cwa). These areas were used in the Bayesian Binary Method (BBM) model implemented in RASP 252 (Yu, Blair \& He, 2020) to investigate the biogeographic history of the selected four Nicotiana 253 species. BBM infers ancestral area using a full hierarchical Bayesian approach and hypothesizes a 254 special "null distribution", meaning that an ancestral range contains none of the unit areas 255 (Ronquist 2004). The analysis was performed on the BEAST maximum clade credibility tree using 256 default settings, i.e. fixed JC + G (Jukes-Cantor + Gamma) with null root distribution. Ancestral 257 area reconstruction for each node was manually plotted on the BEAST tree using pie charts. 258 Species distributions were determined from data stored in the Solanaceae Source Database 259 (http://solanaceaesource.org/) and Global Biodiversity Information Facility (GBIF) 260 (https://www.gbif.org/).

261 3. RESULTS

262 3.1. Characteristics of Nicotiana plastid genomes

263 The genome size of the assembled complete plastid genomes ranged between 155,689 bp $(N$. 264 paniculata) and 156,022 bp (N. obtusifolia), while reads provided 327 to 1,951x coverage (Table 265 S1). Genomes harbored 133 unique genes, of which 18 genes were duplicated in the IR region 266 (Table S2, Fig.1a). Out of 133 genes, 85 were protein-coding, 37 were tRNA genes and 8 were 
267 rRNA genes. Among 18 duplicated genes in the IR region, 7 were protein-coding, 7 were tRNA 268 genes and 4 were rRNA genes. From the protein-coding genes, 18 contained introns, while rps 12

269

270

271

272

273

274

275

276

277

278

279

280

281

282

283

284

285

286

287

288

289

290

291

292

293

294

295

296 was a trans-spliced gene with its $1^{\text {st }}$ exon found in the LSC and the $2^{\text {nd }}$ and $3^{\text {rd }}$ exons found in the IR region. Structural elements of the IR region also showed the highest GC content (43.2\%) compared to the LSC (35.9\%) and SSC (32.1\%) (Table S1). This finding could be attributed to the presence of tRNA (52.9\%) and rRNA (55.4\%) genes in inverted repeats.

The nucleotide composition comparison of Nicotiana genomes revealed high synteny among all regions, including not only the LSC, SSC, IR and CDSs, but interestingly also in non-coding regions. Detailed comparison of the base composition of each region is shown in Table S3. All amino acid sequences in Nicotiana plastid genomes were rich in AT bases and coded a higher percentage of hydrophobic amino acids compared to acidic amino acids that (Fig. 1b). Codon usage and frequency of amino acids revealed that leucine is the most abundant and cysteine the least encoded amino acid in these genomes (Fig. 1b). At the $3^{\text {rd }}$ codon position the frequency of A/T codons was higher compared to $\mathrm{C} / \mathrm{G}$ (Table S4).

The number of RNA editing sites predicted using PREP-cp varied between 34 and 37, distributed among 15 genes (see Table S3). From these genes, the most RNA-edited sites were possessed by $n d h \mathrm{~B}(9)$, followed by $n d h \mathrm{D}(6-8)$ and $r p o \mathrm{~B}(4)$. The $n d h \mathrm{D}$ gene revealed a fraction of variation among species: N. knightiana, N. rustica and N. paniculata having six RNA editing sites, whereas seven were observed in N. obtusifolia and eight in N. glauca. Most of the RNA editing sites were $\mathrm{C}$ to $\mathrm{U}$ edits on the first and second base of the codons, with the frequency of second base codon edits being much higher. These changes helped in the formation of hydrophobic amino acids, for example valine (V), leucine (L) and phenylalanine (F), with conversions from serine to leucine being the most frequent. (Table S5).

\subsection{IR contraction and expansion}

The JL (LSC/IR) and JS (IR/SSC) border positions of Nicotiana plastid genomes were compared (Fig. 1c) using IRscope (Amiryousefi, Hyvönen \& Poczai, 2018b). The length of the IR regions was similar, ranging from $25,331 \mathrm{bp}$ to $25,436 \mathrm{bp}$, with some expansion. The JLA (IRa/LSC) junction point was located between $t r n \mathrm{H}-\mathrm{GUG}$ and $r p l 2$ among Nicotiana plastid genomes. In $N$. tomentosiformis and N. attenuata, the IR expanded to partially include rps 19, creating a 60 and 54-bp truncated pseudogenic rps 19 copy at JLA (IRa/LSC). Furthermore, infA, $y c f 15$, and a copy 
297 of $y c f 1$ located on the JSB (IRb/SSC) were detected as pseudogenes. The position of $y c f 1$ in the

$298 \mathrm{IRb} / \mathrm{SSC}$ region varied. It left a 33-bp pseudogene in $N$. obtusifolia, a 36-bp pseudogene in $N$.

299 knightiana, N. rustica and N. glauca and a 72-bp pseudogene in N. paniculata.

$300 \quad 3.3$. Non-synonymous $\left(K_{a}\right)$ and synonymous $\left(K_{s}\right)$ substitution rate analysis

301 The synonymous/non-synonymous substitution rate ratio is widely used as an indicator of adaptive 302 evolution or positive selection (Kimura, 1979). We have calculated the $K_{s}, K_{a}$ and $K_{a} / K_{s}$ ratio for 30377 protein-coding genes for five selected Nicotiana species using N. tabacum as a reference. 304 Among the analyzed genes, 31 had $\mathrm{K}_{\mathrm{s}}=0$, 19 had $\mathrm{K}_{\mathrm{a}}=0$, and 39 genes had both $\mathrm{K}_{\mathrm{s}}$ and $\mathrm{K}_{\mathrm{a}}=0$ values. 305 Of the investigated genes, 13 genes showed $\mathrm{K}_{\mathrm{a}} / \mathrm{K}_{\mathrm{s}}>1$ in at least one species (Table S4). We 306 selected these genes for further analysis using FUBAR and MEME. FUBAR estimates the number of nonsynonymous and synonymous substitutions at each codon given a phylogeny, and provides the posterior probability of every codon belonging to a set of classes of $\omega$ (including $\omega=1, \omega<1$ or $\omega>1$ ) (Murrell et al., 2013). MEME estimates the probability for a codon to have undergone episodes of positive evolution, allowing the $\omega$ ratio distribution to vary across codons and branches in the phylogeny. This last attribute allows identification of the proportion of codons that may have been evolving neutrally or under purifying selection, while the remaining codons can also evolve under positive selection (Murrell et al., 2012). The two models indicated positive selection on the codons only found in $a t p \mathrm{~B}, n d h \mathrm{D}, n d h \mathrm{~F}$ and $r p o \mathrm{~A}$ (Table 1). Thus, the methods described suggested six amino acid replacements altogether as candidates for positive selection, of which three were fixed in all Nicotiana, and three were restricted to diverse groups of species (see Table $1)$.

\subsection{Repetitive sequences in novel Nicotiana plastid genomes}

319 Repeat analysis performed with MISA revealed high similarity in chloroplast microsatellites (cpSSRs) ranging from 368 to 384 among the species. The majority of the SSRs in these plastid genomes were mononucleotide rather than trinucleotide or dinucleotide repeats. The most dominant of the SSRs were mononucleotide A/T motifs, while the second most predominant were dinucleotide AT/TA motifs. Mononucleotide SSRs varied from 7- to 17-unit repeats, dinucleotide SSRs varied from 4- to 5-unit repeats, and other SSRs types present mainly in 3-unit repeats. Most SSRs were located in the LSC and were less frequent in the IR and SSC (Fig. S1 and Table S7). 
327 species, ranging from 21 (N. paniculata) to 25 (N. knightiana and N. glauca). Forward (F) and

328 palindromic $(\mathrm{P})$ repeats were abundant in all species, where $N$. glauca had the lowest number of 329 repeats $[9(39 \%)(\mathrm{F})$ and $11(52 \%)(\mathrm{P})]$ and $N$. obtusifolia harbored the highest number of repeats $330[14(56 \%)(\mathrm{F})$ and $11(44 \%)(\mathrm{P})]$. The size of oligonucleotide repeats varied from $30-65 \mathrm{bp}$, and 331 many were found in the intergenomic spacer regions (IGS) of the LSC (Fig. S2 and Table S8). The 332 non-coding IGS regions also contained most of the tandem repeats (Fig. S3).

333

\subsection{Single nucleotide polymorphism and insertion/deletion analyses in Nicotiana}

334 To discover polymorphic regions (mutational hotspots), the CDS, intron and IGS regions of the 335 whole plastid genome of five Nicotiana species were compared. Nucleotide diversity values varied from 0 (ycf3) to 0.306 (rps12 intron region) (Fig. 2). High polymorphism was found in intronic regions (average $\pi=0.1670$ ) compared to IGS $(\pi=0.031)$ and CDS regions (average $\pi=0.002$ ). We further investigated the number and occurrence of substitution types in the plastid genomes using $N$. tabacum as a reference and encountered 509 (N. galuca) to 861 (N. paniculata) substitutions along the entire plastid genome. Most of the conversions were $\mathrm{A} / \mathrm{G}$ and $\mathrm{C} / \mathrm{T}$ single nucleotide polymorphisms (SNPs) (Table 2). A detailed description of the ratio of transition to transversion substitutions (Ts/Tv) can be found in Table S9. In addition to the distribution of SNPs, we examined insertions and deletions (indels) and located 107 (N. rustica) to 143 (N. obtusifolia) polymorphisms across the compared genomes (Table 3). Based on this comparison we successfully determined 20 highly polymorphic regions that might be used as potential markers in Nicotiana species barcoding (Table 4).

\subsection{Phylogenetic analyses}

348 Phylogenetic analysis within Nicotiana plastid genomes was performed with the maximum likelihood method based on 75 selected and concatenated protein-coding genes. Our phylogenetic analyses resulted in a highly resolved tree (Fig. 1d). Almost all the recovered clades have maximum branch support values reconstructed based on alignment size of 75,449 bp with best fit model $\mathrm{GY}+\mathrm{F}+\mathrm{I}+\mathrm{G} 4$. We further concentrated on the species phylogeny of $N$. rustica and putative parental species, where relative divergence times were estimated using a relaxed uncorrelated clock implemented in BEAST. This analysis found that the divergence of $N$. undulata appeared 5.36 million years ago (Ma) (highest posterior density, HPD 6.38-4.43), while N. paniculata 
357 knightiana $0.56 \mathrm{Ma}$ (HPD 0.65-0.46). This analysis showed that the Nicotiana species included in

358 the analysis are not older than the end of the Pliocene and that most subsequent evolution must

359 have occurred in the Pleistocene. The timing of these lineage splits, in addition to the current

360 distributions of four closely related species, were used to infer the progression of migratory steps

361 in RASP (Fig. 3). The most recent common ancestor (MRCA) area illustrated a dispersal event for

362 N. paniculata in Northern (B) and Southern Peru (E) and the vicariance of N. knightiana in Coastal

363 Peru (D). The overall dispersal pattern of the examined species showed a south-to-north expansion

364 pattern from Central Peru to Colombia and Ecuador (N. rustica) to Bolivia (N. undulata).

365 4. Discussion

366 4.1. Molecular evolution of Nicotiana plastid genomes

367 We compared plastid genomes from five Nicotiana species, which revealed similar genomic 368 features. These comparative analyses produced an insight into the phylogeny and evolution of 369 Nicotiana species. The GC content of the novel Nicotiana plastid genomes were similar to those 370 previously reported (Sugiyama et al., 2005; Yukawa, Tsudzuki \& Sugiura, 2006); the GC content 371 was high in the IR, which might be a result of the presence of ribosomal RNA (Qian et al., 2013; 372 Cheng et al., 2017; Zhao et al., 2018). The genome organization, gene order and content also 373 showed high similarity and synteny with sequences previously published for $N$. slyvestris and $N$. 374 tabacum (Sugiyama et al., 2005; Yukawa, Tsudzuki \& Sugiura, 2006). This could be attributed to 375 plastid genomes of land plants having a conserved structure but with diversity prevailing at the 376 border position of LSC/SSC/IR. However, examining the IR junction sites of Nicotiana species 377 also showed similarities with some variation prevalent in $N$. tomentosiformis species, which has $37860 \mathrm{bp}$ in the IRb region, while the $\operatorname{rps} 19$ gene is present entirely in the LSC region compared to 379 the N. tabacum reference. Such fluctuations at the border positions of various regions of the plastid 380 genome might be helpful in determining evolutionary relationships or could be indicators of 381 environmental adaptation of species (Menezes et al., 2018). Liu et al., (2018) reported that the 382 similarities in the junction regions may be useful for explaining the relationship between species, and that plants with a high level of relatedness show minimal fluctuations in the junctions of the 384 plastid genome. In this respect, the high resemblance of the IR junction sites reveals a close 385 relationship of Nicotiana species. 
386 Repeats in the plastid genome are useful in evolutionary studies and play a vital role in genome 387 arrangement (Zhang et al., 2016). We detected the presence of large amounts of mononucleotide

388

389

390

391

392

393

394

395

396

397

398

399

400

401

402

403

404

405

406

407

408

409

410

411

412

413

414

415

repeats (A/T), and trinucleotide SSRs (ATT/TAA) in the five analyzed species of Nicotiana, which may be a result of the A/T-richness of the plastid genome. A similar result was also reported in $N$. otophora (Asaf et al., 2016). In all the species of Nicotiana, the LSC region contained a greater amount of SSRs in comparison to SSC and IR, which has also been demonstrated in other studies of angiosperm plastid genomes ( Asaf et al., 2016; Shahzadi et al., 2019; Mehmood et al., 2019, Yang et al., 2019). To understand molecular evolution, it is important to analyze nucleotide substitution rates (Muse \& Gaut, 1994); in plastid genomes LSC and SSC regions are more prone to substitutions and indels, whereas the IRs are more conserved (Ahmed et al., 2012; Abdullah et al., 2019b). Our results corroborate this finding, indicating the IR region is more conserved, and most of the substitutions occur in the LSC and SSC regions. Similar results have been shown in the plastid genome of yam (Dioscorea polystachya Turcz.) (Cao et al., 2018).

Divergence hotspot regions of the plastid genome could be used to develop accurate, robust and cost-effective molecular markers for population genetics, species barcoding, and evolution studies (Ahmed et al., 2013; Ahmed, 2014; Nguyen et al., 2017). Previous studies identified several polymorphic loci based on a comparison of plastid genomes, which have provided suitable information for the development of further molecular markers (Choi, Chung \& Park, 2016; Li et al., 2018; Menezes et al., 2018). We found 20 polymorphism loci in Nicotiana that were more polymorphic than the frequently used $r b c \mathrm{~L}$, and mat $\mathrm{K}$ markers. For example, inf A, rps 12 intron and $r p s 16-\operatorname{trn} \mathrm{Q}-\mathrm{UUG}$ had nucleotide diversities of $0.2594,0.1527$ and 0.0845 , respectively.

These regions show great potential as markers for population genetics and phylogenetic analyses in the genus Nicotiana.

\subsection{Positive selection on Nicotiana plastid genes}

Plants have evolved complex physiological and biochemical adaptations to adjust and adapt to different environmental stresses. Nicotiana, originating in South America, has spread to many regions of the world and members of the genus have successfully adapted to survive in harsh environmental conditions. This large variation in their distributional range has induced distinctive habits and morphology in inflorescence and flowers, indicative of the physiological specialization to the area where they evolved. Desert ephemeral Nicotiana species are short while subtropical

Peer] reviewing PDF | (2020:01:44924:3:0:NEW 15 Jun 2020) 
416 perennials have tall and robust habits with variable inflorescences ranging from pleiochasial cymes 417 to solitary flowers and diffuse panculate-cymose mixtures. For example, members of Nicotiana 418 section Suaveolentes, evolving in isolation, faced several cycles of harsh climate change. In 419 Australia, the native range of the species, a predominantly warm and wet environment went through intensive aridification (Poczai, Hyvönen \& Symon, 2011). Throughout this climate change and increasing central aridification, many species either retreated to the wetter coastline or adapted to and still survive in this hostile inland environment (Bally et al., 2018). Tobacco plants also developed specialized biosynthetic pathways and metabolites, such as nicotine, which serve complex functions for ecological adaptations to biotic and abiotic stresses, most importantly serving as a defense mechanism against herbivores ( $\mathrm{Xu}$ et al. 2017). Nicotiana is thus a rich reservoir of genetic resources for evolutionary biological research since several members of the genus have gone through changing climatic events and adapted to environmental fluctuations.

The patterns of synonymous $\left(\mathrm{K}_{\mathrm{s}}\right)$ and non-synonymous $\left(\mathrm{K}_{\mathrm{a}}\right)$ substitution of nucleotides are essential markers in evolutionary genetics defining slow and fast evolving genes (Kimura, 2006). $\mathrm{K}_{\mathrm{a}} / \mathrm{K}_{\mathrm{s}}$ values $>1,=1$, and $<1$ indicate positive selection, neutral evolution and purifying selection, respectively (Lawrie et al., 2013). Many proteins and RNA molecules encoded by plastid genomes have undergone purifying selection since they are involved in important functions of plant metabolism, self-replication, and photosynthesis and therefore play a pivotal role in plant survival (Piot et al., 2018). Departure from the main purifying selection in the case of plastid genes might happen in response to certain environmental changes when advantageous genetic mutations can contribute to better survival and adaptation. The $\mathrm{K}_{\mathrm{a}} / \mathrm{K}_{\mathrm{s}}$ ratios in our analysis indicate changes in selective pressures. The genes $a t p \mathrm{~B}, n d h \mathrm{D}, n d h \mathrm{~F}$ and $r p o \mathrm{~A}$ had greater $\mathrm{K}_{\mathrm{a}} / \mathrm{K}_{\mathrm{s}}$ values $(>1)$, possibly due to positive selective pressure as a result of specific environmental conditions. This was conclusively supported by an integrative analysis using Fast Unconstrained Bayesian AppRoximation (FUBAR) and Mixed Effects Model of Evolution (MEME) methods, which identified a set of positively selected codons in these genes.

442 These genes are involved in different plastid functions, such as DNA replication (rpoA) and photosynthesis $(a t p \mathrm{~B}, n d h \mathrm{D}$ and $n d h \mathrm{~F})$. The rpoA gene encodes the alpha subunit of PEP, which is believed to predominantly transcribe photosynthesis genes (Hajdukiewicz, Allison \& Maliga, 1997). The transcripts of plastid genes encoding the PEP core subunits are transiently accumulated 446 during leaf development (Kusumi et al., 2011), thus the entire rpoA polycistron is essential for 
447 chloroplast gene expression and plant development (Zhang et al., 2018). The housekeeping gene 448 atp $\mathrm{B}$ encodes the $\beta$-subunit of the ATP synthase complex, which has a highly conserved structure 449 that couples proton translocation across membranes with the synthesis of ATP (Gatenby, Rothstein 450 \& Nomura, 1989), which is the main source of energy for the functioning of plant cells. In 451 chloroplasts, linear electron transport mediated by PSII and PSI produces both ATP and NADPH, 452 whereas PSI cyclic electron transport preferentially contributes to ATP synthesis without the 453 accumulation of NADPH (Peng \& Shikanai, 2011). Chloroplast NDH monomers are sensitive to 454 high light stress, suggesting that the $n d h$ genes encoding NAD(P)H dehydrogenase (NDH) may 455 also be involved in stress acclimation through the optimization of photosynthesis (Casano, Martín 456 \& Sabater, 2001; Martin et al., 2002; Rumeau, Peltier \& Cournac, 2007). During acclimation to 457 different light environments, many plants change biochemical composition and morphology 458 (Terashima et al., 2005). The highly responsive regulatory system controlled by cyclic electron 459 transport around PSI could optimize photosynthesis and plant growth under naturally fluctuating 460 light (Yamori, 2016). When demand for ATP is higher than for NADPH (e.g., during 461 photosynthetic induction, at high or low temperatures, at low $\mathrm{CO}_{2}$ concentration, or under 462 drought), cyclic electron transport around PSI is likely to be activated (Yamori, 2016; Yamori \& 463 Shikanai, 2016). Thus, positive selection acting on ATP synthase and NAD(P)H dehydrogenase 464 encoding genes is probably evidence for adaptation to novel ecological conditions in Nicotiana.

465

466

467

468

469

470

471

472

473

474

475

476

477

These findings are further supported by our observation that RNA editing sites occur frequently in Nicotiana $n d h$ genes (Table S3). It has been shown that $n d h \mathrm{~B}$ mutants under lower air humidity conditions or following exposure to ABA present reduced levels of photosynthesis, likely mediated through stomatal closure triggered under these conditions (Horvath et al., 2000). Therefore, a protein structure modification resulting from a loss or decrease in RNA editing events could affect adaptations to stress conditions or cause other unknown changes (Rodrigues et al., 2017). Previous studies have demonstrated that abiotic stress influences the editing process and consequently plastid physiology (Nakajima \& Mulligan, 2001). Alterations in editing site patterns resulting from abiotic stress could be associated with susceptibility to photo-oxidative damage (Rodrigues et al., 2017) and indicate that Nicotiana species experienced abiotic stresses during their evolution, which resulted in positive selection of some plastid genes. Up to this point, positive selection has rarely been detected in plastid genes except for $\operatorname{clpP}$ (Erixon \& Oxelman, 2008), $n d h \mathrm{~F}$ (Peng et al., 2011), matK (Hao, Chen \& Xiao, 2010) and rbcL (Kapralov et al., 2011). However, Piot et al. 
478 (2018) showed that one-third of the plastid genes in 113 species of grasses (Poaceae) evolved 479 under positive selection. This indicates that positive selection is overlooked among diverse groups 480 of plant taxa.

481 4.3. Phylogenetic relationships and the origin of tetraploid Nicotiana rustica

482 Our comparative plastid genome analysis revealed that the maternal parent of the tetraploid $N$. 483 rustica was the common ancestor of $N$. paniculata and $N$. knightiana, with the latter species being

484

485

486

487

488

489

490

491

492

493

494

495

496

497

498

499

500

501

502

503

504

505

506

507 more closely related to $N$. rustica. The relaxed molecular clock analyses estimated that the speciation event between $N$. rustica and $N$. knightiana appeared $\sim 0.56 \mathrm{Ma}$ (HPD 0.65-0.46), in line with previous findings (Sierro et al., 2018). Comparative analysis of the genomes of four related Nicotiana species revealed that N. rustica inherited about $41 \%$ of its nuclear genome from its paternal progenitor, $N$. undulata, and the rest from its maternal progenitor, the common ancestor of $N$. paniculata and N. knightiana (Sierro et al., 2018), which has also been confirmed by our study. We also revealed that N. knightiana is more closely related to N. rustica than N. paniculata, which can be further corroborated by the distribution of indels highlighted in the present study. The paternal inheritance of plastid genomes was observed in Nicotiana under certain stressed conditions (Medgyesy, Fejes \& Maliga, 1985; Medgyesy, Páy \& Márton, 1986; Thang and Medgyesy, 1989; Avni and Edelman, 1991; Ruf, Karcher \& Bock, 2007; Thyssen, Svab \& Maliga, 2012). Such low-frequency paternal leakage of plastids via pollen was suggested to be universal in plants with strict maternal plastid inheritance (Azagiri and Maliga 2007). Thus, we expect that the plastids in the putative parents of $N$. rustica are maternally inherited. Medgyesy, Páy \& Márton (1986) observed the paternal transmission of plastids in $N$. plumbaginifolia Viv., but they concluded that plants carried maternal mitochondria. Further studies investigating the parental origins of Nicotiana species should also focus on mitochondrial genomes excluding possible lowfrequency paternal plastid inheritance.

The biogeographical analysis suggests that $N$. undulata and $N$. paniculata evolved in North/Central Peru, while N. rustica developed in Southern Peru and separated from N. knightiana, which adapted to the Southern coastal climatic regimes. Positively selected plastid genes with functions such as DNA replication (rpoA) and photosynthesis $(a t p \mathrm{~B}, n d h \mathrm{D}$ and $n d h \mathrm{~F})$ might have been associated with successful adaptation to, for example, a coastal environment. However, our results are tentative, as our study lacks data for several broad ecological variables, including variation in 
508 salinity, island versus mainland, and East versus West of the Andes. We aim to highlight that many 509 potential environmental variables might be highly correlated with speciation processes in 510 Nicotiana, as has been demonstrated in the same region for another Solanaceae group in the tomato 511 clade (Solanum sect. Lycopersicon), where amino acid differences in genes associated with 512 seasonal climate variation and intensity of photosynthetically active radiation have been correlated 513 with speciation processes (Pease et al., 2016). Another example of rapid adaptive radiation from 514 the family is the genus Nolana L.f., where several clades gained competitive advantages in water515 dependent environments by succeeding and diverging in Peru and Northern Chile (Dillon et al., 516 2009). In the case of $N$. rustica and related species, we assume that diversification was driven by 517 the ecologically variable environments of the Andes. Our molecular clock analysis provides 518 evidence for recent species diversification in the Pleistocene and Pliocene while substantial 519 climatic transitions in Peru predate these events. For example, the uplift of the central region of 520 the Andes and the formation of the Peruvian coastal desert ended $14-150$ Mya (Hoorn et al., 521 2010; Gerreaud, Molina \& Farias, 2010), before the geographical and ecological expansion of $N$. 522 rustica and related parental species.

523 The dispersal of $N$. rustica and related species shows a south-to-north range expansion and 524 diversification which has been suggested by phylogenies of other plant and animal groups in the 525 Central Andes (Picard, Sempere \& Plantard, 2008; Lueber \& Weigend, 2014). Based on the south526 to-north progression scenario, habitats located at high altitudes were first available for colonization 527 in the south, recently continuing to northward. Erosion and orogenic progression caused dispersal 528 barriers of species colonizing these high habitats to diversify in a south-to-north pattern, frequently 529 following allopatric speciation. Thus, for taxonomic groups currently residing throughout a large 530 portion of the high Andes, a south-to-north speciation pattern is expected (Doan, 2003). In this 531 case, the most basal species ( $N$. undulata) has more southern geographic ranges, and the most 532 derived species (N. rustica) has more northern geographic ranges, except for N. knightiana, which 533 presumably colonized the coastal range of Peru. Although the four Nicotiana species examined 534 show overlaps in their distribution, it is probable that speciation was caused by fragmentation of 535 populations during the glacial period (see Simpson, 1975). Utilizing fewer chloroplast loci for 536 phylogenetic analyses of plant species may limit the solution of phylogenetic relationships, 537 specifically at low taxonomic levels (Hilu \& Alice, 2001; Majure et al., 2012). Previously, genus 538 Nicotiana was subdivided into 13 sections using multiple chloroplast markers, i.e. trnL intron and 
$539 \operatorname{trn} \mathrm{L}-\mathrm{F}$ spacer, $\operatorname{trnS}-\mathrm{G}$ spacer and two genes, $n d h \mathrm{~F}$ and matK (Clarkson et al., 2004). Recently,

540 inference of phylogeny based on complete plastid genomes has provided deep insight into the 541 phylogeny of certain families and genera (Henriquez et al., 2014; Amiryousefi, Hyvönen \& Poczai, 542 2018a; Abdullah et al., 2020). Here, we reconstructed a phylogenetic tree for eleven species of 543 genus Nicotiana that belong to nine sections (Clarkson et al., 2004) based on 75 protein-coding 544 genes by using $S$. dulcamara as an outgroup, which attests the previous classification of genus 545 Nicotiana with high bootstrapping values. Species of each section are well resolved whereas $N$. 546 tabacum of section Nicotiana, and N. sylvestris of section Sylvestres, show close resemblance. $N$. 547 paniculata and $N$. knightiana belong to section Paniculatae and appeared to reflect the maternal 548 ancestry of these species relative to N. rustica of section Rusticae. Overall, our phylogenetic 549 analyses support the previous classification of genus Nicotiana, and corroborates that plastid 550 genomic resources can provide further support for highly resolved phylogenies.

\section{5. Conclusion}

552 In the present study, we assembled, annotated and analyzed the whole cp genome sequence of five

553 Nicotiana species. The genomic structure and organization of their plastid genome was similar to 554 those of previously reported Solanaceae plastid genomes. Divergences of LSC, SSC and IR region 555 sequences were identified, as well as the distribution and location of repeat sequences. The 556 identified mutational hotspots sequences could be utilized as potential molecular markers to 557 investigate phylogenetic relationships in the genus. As we demonstrated in our study to elucidate 558 the maternal genome origins of N. rustica, our results could provide further help in understanding 559 the evolutionary history of tobaccos.

\section{Acknowledgements}

561 We thank Kenneth Quek and Kathryn Rannikko for editing the manuscript.

\section{Competing interest}

563 The authors declare that they have no conflict of interest.

\section{Authors contributions}

565 Furrukh Mehmood: Conceptualization, Genome assembly and annotation, Data analysis, Data 566 interpretation, prepared figures and tables, Manuscript drafting and editing. 
567 Abdullah: Genome annotation, Data analysis, Data interpretation, Manuscript drafting.

568 Zartasha Ubaid: Data analysis, Data interpretation, Manuscript drafting.

569 Iram Shehzadi: Data analysis, Data interpretation, Manuscript drafting.

570 Ibrar Ahmed: Conceptualization, Manuscript editing.

571 Mohammad Tahir Waheed: Conceptualization, Manuscript editing.

572 Péter Poczai: Supervision, carried out selection tests and phylogenetic analysis, prepared figures

573 and tables, authored and reviewed drafts of the paper, approved the final draft.

574 Bushra Mirza: Supervision, authored or reviewed drafts of the paper, approved the final draft.

575 Péter Poczai and Bushra Mirza, contributed equally to the manuscript.

576

577 References

578

579

580

581

582

583

584

585

586

587

588

589

590

Abdullah, Mehmood F, Shahzadi I, Waseem S, Mirza B, Ahmed I, Waheed MT. 2020. Chloroplast genome of Hibiscus rosa-sinensis (Malvaceae): Comparative analyses and identification of mutational hotspots. Genomics 112:581-591. DOI: 10.1016/j.ygeno.2019.04.010.

Abdullah, Shahzadi I, Mehmood F, Ali Z, Malik MS, Waseem S, Mirza B, Ahmed I, Waheed MT. 2019a. Comparative analyses of chloroplast genomes among three Firmiana species: Identification of mutational hotspots and phylogenetic relationship with other species of Malvaceae. Plant Gene 19:100199

Abdullah, Waseem S, Mirza B, Ahmed I, Waheed MT. 2019b. Comparative analyses of chloroplast genome in Theobroma cacao and Theobroma grandiflorum. Biologia DOI: https://doi.org/10.2478/s11756-019-00388-8

Ahmed I. 2014. Evolutionary dynamics in taro. Massey University, Palmerston North, New Zealand, PhD Thesis 
591

592

593

594

595

596

597

598

599

600

601

602

603

604

605

606

607

608

609

610

611

612

613

614

615

616

617

Ahmed I, Biggs PJ, Matthews PJ, Collins LJ, Hendy MD, Lockhart PJ. 2012. Mutational dynamics of aroid chloroplast genomes. Genome Biology and Evolution 4:1316-1323. DOI: $10.1093 / \mathrm{gbe} / \mathrm{evs} 110$.

Ahmed I, Matthews PJ, Biggs PJ, Naeem M, Mclenachan PA, Lockhart PJ. 2013. Identification of chloroplast genome loci suitable for high-resolution phylogeographic studies of Colocasia esculenta (L.) Schott (Araceae) and closely related taxa. Molecular Ecology Resources 13:929-937. DOI: 10.1111/1755-0998.12128.

Amiryousefi A, Hyvönen J, Poczai P. 2018a. The chloroplast genome sequence of bittersweet (Solanum dulcamara): Plastid genome structure evolution in Solanaceae. PLoS ONE 13:123. DOI: 10.1371/journal.pone.0196069.

Amiryousefi A, Hyvönen J, Poczai P. 2018b. IRscope: an online program to visualize the junction sites of chloroplast genomes. Bioinformatics 34:3030-3031. DOI: 10.1093/bioinformatics/bty220.

Aoki S, Ito M. 2000. Molecular phylogeny of Nicotiana (Solanaceae) based on the nucleotide sequence of the matK gene. Plant Biology 2:316-324. DOI: 10.1055/s-2000-3710.

Asaf S, Khan AL, Khan AR, Waqas M, Kang S-M, Khan MA, Lee S-M, Lee I-J. 2016. Complete chloroplast genome of Nicotiana otophora and its comparison with related species. Frontiers in Plant Science 7:1-12. DOI: 10.3389/fpls.2016.00843.

Bally J, Jung H, Mortimer C, Naim F, Philips JG, Hellens R, Bombarely A, Goodin MM, Waterhouse PM. 2018. The rise and rise of Nicotiana benthamiana: a plant for all reasons. Annual Review of Phytopathology 56: 405-426. DOI: 10.1146/annurev-phyto-080417050141.

Beier S, Thiel T, Münch T, Scholz U, Mascher M. 2017. MISA-web: a web server for microsatellite prediction. Bioinformatics 33:2583-2585. DOI: 10.1093/bioinformatics/btx198.

Benjamini Y, Hochberg Y. 1995. Controlling the false discovery rate: a practical and powerful approach to multiple testing. Journal of the Royal Statistical Society: Series B 57:289-300. 
618

619

620

621

622

623

624

625

626

627

628

629

630

631

632

633

634

635

636

637

638

639

640

641

642

643

644

645

646

Bindler G, Plieske J, Bakaher N, Gunduz I, Ivanov N, van der Hoeven R, Ganal M, Donini P. 2011. A high density genetic map of tobacco (Nicotiana tabacum L.) obtained from large scale microsatellite marker development. Theoretic and Applied Genetics 123: 219

Benson G. 1999. Tandem repeats finder: A program to analyze DNA sequences. Nucleic Acids Research 27: 573-580. DOI: 10.1093/nar/27.2.573.

Cao J, Jiang D, Zhao Z, Yuan S, Zhang Y, Zhang T, Zhong W, Yuan Q, Huang L. 2018. Development of chloroplast genomic resources in Chinese yam (Dioscorea polystachya). BioMed Research International. DOI: 10.1155/2018/6293847

Casano LM, Martín M, Sabater B. 2001. Hydrogen peroxide mediates the induction of chloroplastic Ndh complex under photooxidative stress in Barley. Plant Physiology 125:1450-1458. DOI: 10.1104/pp.125.3.1450.

Chase MW, Knapp S, Cox A V., Clarkson JJ, Butsko Y, Joseph J, Savolainen V, Parokonny AS. 2003. Molecular systematics, GISH and the origin of hybrid taxa in Nicotiana (Solanaceae). Annals of Botany 92:107-127. DOI: 10.1093/aob/mcg087.

Cheng H, Li J, Zhang H, Cai B, Gao Z, Qiao Y, Mi L. 2017. The complete chloroplast genome sequence of strawberry (Fragaria $\times$ ananassa Duch.) and comparison with related species of Rosaceae. PeerJ 5:e3919 DOI: 10.7717/peerj.3919.

Choi KS, Chung MG, Park S. 2016. The complete chloroplast genome sequences of three veroniceae species (Plantaginaceae): comparative analysis and highly divergent regions. Frontiers in Plant Science 7:1-8. DOI: 10.3389/fpls.2016.00355.

Clarkson JJ, Lim KY, Kovarik A, Chase MW, Knapp S, Andrew RL. 2005. Long-term genome diploidization in allopolyploid Nicotiana section Repandae (Solanaceae). New Phytologist 168:241-252

Clarkson JJ, Dodsworth S, Chase MW. 2017. Time-calibrated phylogenetic trees establish a lag between polyploidisation and diversification in Nicotiana (Solanaceae). Plant Systematics and Evolution 303:1001-1012. DOI: 10.1007/s00606-017-1416-9.

Clarkson JJ, Knapp S, Garcia VF, Olmstead RG, Leitch AR, Chase MW. 2004. Phylogenetic relationships in Nicotiana (Solanaceae) inferred from multiple plastid DNA regions. Molecular Phylogenetics and Evolution 33:75-90. 
647 Cooper G. 2000. Chloroplasts and other plastids in the cell: A molecular approach. Sunderland 648 (MA): Sinauer Associates.

649

650

651

652

653

654

655

656

657

658

659

660

661

662

663

664

665

666

667

668

669

670

671

672

673

674

Couvreur TLP, Chatrou LW, Sosef MSM, Richardson JE. 2008. Molecular phylogenetics reveal multiple tertiary vicariance origins of the African rain forest trees. BMC Biology 6: 54.

Daniell H. 2007. Transgene containment by maternal inheritance: Effective or elusive? Proceedings of the National Academy of Sciences USA 104: 6879-6880. DOI: 10.1073/pnas.0702219104.

Daniell H, Lin C-S, Yu M, Chang W-J. 2016. Chloroplast genomes: diversity, evolution, and applications in genetic engineering. Genome Biology 17:134. DOI: 10.1186/s13059-0161004-2.

Delport W, Poon AFY, Frost SDW, Kosakovsky Pond SL. 2010. Datamonkey 2010: A suite of phylogenetic analysis tools for evolutionary biology. Bioinformatics 26: 2455-2457. DOI: 10.1093/bioinformatics/btq429.

Dereeper A, Guignon V, Blanc G, Audic S, Buffet S, Chevenet F, Dufayard J-F, Guindon S, Lefort V, Lescot M, Claverie J-M, Gascuel O. 2008. Phylogeny.fr: robust phylogenetic analysis for the non-specialist. Nucleic Acids Research 36:W465-W469. DOI: $10.1093 / \mathrm{nar} / \mathrm{gkn} 180$

Dillon MO, Tu T, Xie L, Quipuscia Silvestre V. 2009. Biogeographic diversification in Nolana (Solanaceae), a ubiquitous member of the Atacama and Peruvian Deserts along the western coast of South America. Journal of Systematics and Evolution 47: 457-476

Doan TM. 2003. A south-to-north biogeographic hypothesis for Andean speciation: evidence from the lizard genus Proctoporus (Reptilia, Gymnophthalmidae). Journal of Biogeography 30: 361-374

Drummond AJ, Ho SYW, Phillips MJ, Rambaut A. 2006. Relaxed phylogenetics and dating with confidence. PLoS Biology 4: e88

Drummond AJ, Suchard M, Xie D, Rambaut A. 2012. Bayesian phylogenetics with BEAUti and the BEAST 1.7. Molecular Biology and Evolution 29:1969 - 1973

Erixon P, Oxelman B. 2008. Whole-gene positive selection, elevated synonymous substitution 
675

676

677

678

679

680

681

682

683

684

685

686

687

688

689

690

691

692

693

694

695

696

697

698

699

700

701

702

rates, duplication, and indel evolution of the chloroplast clpP1 gene. PLoS ONE 3: e1386. DOI: 10.1371/journal.pone.0001386.

Evans M, Aubriot X, Hearn D, Lanciaux M, Lavergne S, Cruaud C, Lowry II PP, Haevermans R. 2014. The evolution of succulence: insights from a remarkable radiation in Madagascar. Systematic Biology 63: 698 - 711.

Gatenby AA, Rothstein SJ, Nomura M. 1989. Translational coupling of the maize chloroplast $a t p \mathrm{~B}$ and atpE genes. Proceedings of the National Academy of Sciences USA 86: 4066-4070.

Gerreaud RD, Molina A, Farias M. 2010. Andean uplift, ocean cooling and Atacama hyperaridity: a climate modeling perspective. Earth and Plenetary Science Letters 292:39_50

Goodin MM, Zaitlin D, Naidu RA, Lommel SA. 2008. Nicotiana benthamiana: Its history and future as a model for plant-pathogen interactions. Molecular Plant-Microbe Interactions 21: 1015-1026. DOI: 10.1094/MPMI-21-8-1015.

Goodspeed TH. 1954. The Genus Nicotiana. Chronica Botanica, New York, USA

Greiner S, Lehwark P, Bock R. 2019. OrganellarGenomeDRAW (OGDRAW) version 1.3.1: expanded toolkit for the graphical visualization of organellar genomes. Nucleic Acids Research 47:W59-W64. DOI: 10.1093/nar/gkz238.

Hajdukiewicz PTJ, Allison LA, Maliga P. 1997. The two RNA polymerases encoded by the nuclear and the plastid compartments transcribe distinct groups of genes in tobacco plastids. EMBO Journal 16: 4041-4048. DOI: 10.1093/emboj/16.13.4041.

Hao DC, Chen SL, Xiao PG. 2010. Molecular evolution and positive Darwinian selection of the chloroplast maturase matK. Journal of Plant Research 123:241-247. DOI: 10.1007/s10265009-0261-5.

Henriquez CL, Arias T, Pires JC, Croat TB, Schaal BA. 2014. Phylogenomics of the plant family Araceae. Molecular Phylogenetics and Evolution 75:91-102. DOI: 10.1016/j.ympev.2014.02.017.

Henriquez CL, Abdullah, Ahmed I, Carlsen MM, Zuluaga A, Croat TB, Mckain MR. 2020a. Molecular evolution of chloroplast genomes in Monsteroideae (Araceae). Planta 251:72. 
DOI: $10.1007 / \mathrm{s} 00425-020-03365-7$.

Hilu KW, Alice LA. 2001. A phylogeny of Chloridoideae (Poaceae) based on matK sequences. Systematic Botany 26: 386-405.

Hoang DT, Chernomor O, von Haeseler A, Minh BQ, Vinh LS. 2018. UFBoot2: improving the ultrafast bootstrap approximation. Molecular Biology and Evolution 35: 518-522.

Hoorn C, Wesselingh FP, ter Steege H, Bermudez MA, Mora A, Sevink J, Sanmartín I, Sanchez-Meseguer A, Anderson CL, Figueiredo JP, Jaramillo C, Riff D, Negri FR, Hooghiemstra H, Lundberg J, Stadler T, Särkinen T, Antonelli A. 2010. Amazonia through tie: Andean uplift, climate change, landscape evolution, and biodiversity. Science 330: $927-931$

Horvath EM, Peter SO, Joet T, Rumeau D, Cournac L, Horvath G V., Kavanagh TA, Schafer C, Peltier G, Medgyesy P. 2000. Targeted inactivation of the plastid $n d h \mathrm{~B}$ gene in tobacco results in an enhanced sensitivity of photosynthesis to moderate stomatal closure. Plant Physiology 123: 1337-1350.

Iram S, Hayat MQ, Tahir M, Gul A, Abdullah, Ahmed I. 2019. Chloroplast genome sequence of Artemisia scoparia: Comparative analyses and screening of mutational hotspots. Plants 8:476. DOI: doi:10.3390/plants8110476.

Jheng C-F, Chen T-C, Lin J-Y, Chen T-C, Wu W-L, Chang C-C. 2012. The comparative chloroplast genomic analysis of photosynthetic orchids and developing DNA markers to distinguish Phalaenopsis orchids. Plant Science 190:62-73. DOI: 10.1016/j.plantsci.2012.04.001.

Jin S, Daniell H. 2015. The Engineered Chloroplast Genome Just Got Smarter. Trends in Plant Science 20: 622-640 DOI: 10.1016/j.tplants.2015.07.004

Kalyaanamoorthy S, Minh BQ, Wong TKF, von Haeseler A, Jermiin LS. 2017. ModelFinder: fast model selection for accurate phylogenetic estimates. Nature Methods 14: 587-589. DOI: $10.1038 /$ nmeth.4285

Kapralov M V., Kubien DS, Andersson I, Filatov DA. 2011. Changes in rubisco kinetics during the evolution of C4 Photosynthesis in Flaveria (Asteraceae) are associated with positive selection on genes encoding the enzyme. Molecular Biology and Evolution 28: 1491-1503. 
732

733

734

735

736

737

738

739

740

741

742

743

744

745

746

747

748

749

750

751

752

753

754

755

756

757

758

759

DOI: $10.1093 / \mathrm{molbev} / \mathrm{msq} 335$.

Katoh K, Standley DM. 2013. MAFFT multiple sequence alignment software version 7: Improvements in performance and usability. Molecular Biology and Evolution 30: 772-780. DOI: $10.1093 / \mathrm{molbev} / \mathrm{mst} 010$.

Kearse M, Moir R, Wilson A, Stones-Havas S, Cheung M, Sturrock S, Buxton S, Cooper A, Markowitz S, Duran C, Thierer T, Ashton B, Meintjes P, Drummond A. 2012. Geneious Basic: An integrated and extendable desktop software platform for the organization and analysis of sequence data. Bioinformatics 28:1647-1649. DOI: 10.1093/bioinformatics/bts199.

Kent WJ. 2002. BLAT - The BLAST-like alignment tool. Genome Research 12: 656-664. DOI: 10.1101/gr.229202. Article published online before March 2002.

Kimura M. 1979. Model of effectively neutral mutations in which selective constraint is incorporated. Proceedings of the National Academy of Sciences of the USA 76: 3440-3444 DOI: 10.1073/pnas.76.7.3440.

Kimura M. 2006. Model of effectively neutral mutations in which selective constraint is incorporated. Proceedings of the National Academy of Sciences USA 76: 3440-3444. DOI: 10.1073/pnas.76.7.3440.

Knapp S, Chase MW, Clarkson JJ. 2004. Nomenclatural changes and a new sectional classification in Nicotiana (Solanaceae). Taxon 53: 73-82. DOI: 10.2307/4135490.

Kurtz S, Choudhuri J V, Ohlebusch E, Schleiermacher C, Stoye J, Giegerich R. 2001. REPuter: the manifold applications of repeat analysis on a genomic scale. Nucleic Acids Research 29:4633-4642.

Kusumi K, Sakata C, Nakamura T, Kawasaki S, Yoshimura A, Iba K. 2011. A plastid protein NUS1 is essential for build-up of the genetic system for early chloroplast development under cold stress conditions. Plant Journal 68:1039-1050. DOI: 10.1111/j.1365313X.2011.04755.x.

Kell KT. 1966. Folk Names for Tobacco. The Journal of American Folklore 79:590-599. DOI: $10.2307 / 538224$. 
760

761

762

763

764

765

766

767

768

769

770

771

772

773

774

775

776

777

778

779

780

781

782

783

784

785

786

787

Kovarik A, Matyasek R, Lim KY, Skalická K, Koukalová B, Knapp S, Chase M, Leitch AR. 2004. Concerted evolution of $18-5.8-26 \mathrm{~S}$ rDNA repeats in Nicotiana allotetraploids. Biological Journal of the Linnean Society 82:615-625 DOI: 10.1111/j.10958312.2004.00345.x.

Kovarik A., Renny-Byfield S., Grandbastien MA., Leitch A. 2012. Evolutionary Implications of Genome and Karyotype Restructuring in Nicotiana tabacum L. In: Soltis P., Soltis D. (eds) Polyploidy and Genome Evolution. Springer, Berlin, Heidelberg pp.209-224

Laslett D, Canback B. 2004. ARAGORN, a program to detect tRNA genes and tmRNA genes in nucleotide sequences. Nucleic Acids Research 32:11-16. DOI: 10.1093/nar/gkh152.

Lawrie DS, Messer PW, Hershberg R, Petrov DA. 2013. Strong purifying selection at synonymous sites in D. melanogaster. PLoS Genetics 9:33-40. DOI: 10.1371/journal.pgen.1003527.

Leitch IJ, Hanson L, Lim KY, Kovarik A, Chase MW, Clarkson JJ, Leitch AR. 2008. The ups and downs of genome size evolution in polyploid species of Nicotiana (Solanaceae). Annals of Botany 101:805-814. DOI: 10.1093/aob/mcm326.

Lemoine F, Correia D, Lefort V, Doppelt-Azeroual O, Mareuil F, Cohen-Boulakia S, Gascuel O. 2019. NGPhylogeny.fr: new generation phylogenetic services for non-specialists. Nucleic Acids Research 47:W260-W265. DOI: 10.1093/nar/gkz303.

Li H, Durbin R. 2009. Fast and accurate short read alignment with Burrows-Wheeler transform. Bioinformatics 25:1754-1760. DOI: 10.1093/bioinformatics/btp324.

Li Y, Zhang Z, Yang J, Lv G. 2018. Complete chloroplast genome of seven Fritillaria species, variable DNA markers identification and phylogenetic relationships within the genus. PLoS ONE 13:e0194613 DOI: 10.1371/journal.pone.0194613. 3.

Lim KY, Matyasek R, Kovarik A, Leitch AR. 2004. Genome evolution in allotetraploid Nicotiana. Biological Journal of the Linnean Society 82:599-606 DOI: 10.1111/j.10958312.2004.00344.x. 82:599-606.

Lim KY, Kovarik A, Matyasek R, Chase MW, Clarkson JJ, Grandbastien MA, Leitch AR. 2007. Sequence of events leading to near-complete genome turnover in allopolyploid 
788

789

790

791

792

793

794

795

796

797

798

799

800

801

802

803

804

805

806

807

808

809

810

811

812

813

814

815

816

Nicotiana within five million years. New Phytologist 175:756-763. DOI: 10.1111/j.14698137.2007.02121.x.

Liu L, Wang Y, He P, Li P, Lee J, Soltis DE, Fu C. 2018. Chloroplast genome analyses and genomic resource development for epilithic sister genera Oresitrophe and Mukdenia (Saxifragaceae), using genome skimming data. BMC Genomics 19:235. DOI: 10.1186/s12864-018-4633-x.

Lowe TM, Chan PP. 2016. tRNAscan-SE On-line: integrating search and context for analysis of transfer RNA genes. Nucleic Acids Research 44:W54-W57. DOI: 10.1093/nar/gkw413.

Lewis RS. 2011. Nicotiana. In: Kole C (ed) Wild crop relatives: genomic and breeding resources plantation and ornamental crops. Springer, New York, USA.

Lester RN, Hawkes JG. 2001. Solanaceae. In: Hanelt P and Institute of Plant Genetics and Crop Plant Research (eds) Mansfeld's encyclopedia of agriculture and horticultural crops (Except Oranamentals), vol 4. Springer, Berlin. pp. 1790-1856.

Luebert F, Weigend M. 2014. Phylogenetic insights into Andean plant diversification. Frontiers in Ecology and Evolution 2: 27

Majure LC, Puente R, Patrick Griffith M, Judd WS, Soltis PS, Soltis DE. 2012. Phylogeny of Opuntia s.s. (Cactaceae): Clade delineation, geographic origins, reticulate evolution. American Journal of Botany 99:847-864. DOI: 10.3732/ajb.1100375.

Martin W, Rujan T, Richly E, Hansen A, Cornelsen S, Lins T, Leister D, Stoebe B, Hasegawa M, Penny D. 2002. Evolutionary analysis of Arabidopsis, cyanobacterial, and chloroplast genomes reveals plastid phylogeny and thousands of cyanobacterial genes in the nucleus. Proceedings of the National Academy of Sciences of the USA 99:12246-51. DOI: 10.1073/pnas. 182432999.

Mehmood F, Abdullah, Shahzadi I, Ahmed I, Waheed MT, Mirza B. 2019. Characterization of Withania somnifera chloroplast genome and its comparison with other selected species of Solanaceae. Genomics 112: 1522-1530 DOI: 10.1016/J.YGENO.2019.08.024.

Menezes APA, Resende-Moreira LC, Buzatti RSO, Nazareno AG, Carlsen M, Lobo FP, Kalapothakis E, Lovato MB. 2018. Chloroplast genomes of Byrsonima species (Malpighiaceae): Comparative analysis and screening of high divergence sequences. 
Scientific Reports 8:1-12. DOI: 10.1038/s41598-018-20189-4.

818

819

820

821

822

823

824

825

826

827

828

829

830

831

832

833

834

835

836

837

838

839

840

841

842

843

844

845

Milne I, Bayer M, Cardle L, Shaw P, Stephen G, Wright F, Marshall D. 2009. Tablet-next generation sequence assembly visualization. Bioinformatics 26:401-402. DOI: 10.1093/bioinformatics/btp666.

Mower JP. 2009. The PREP suite: Predictive RNA editors for plant mitochondrial genes, chloroplast genes and user-defined alignments. Nucleic Acids Research 37:W253-W259. DOI: $10.1093 /$ nar/gkp337.

Murrell B, Wertheim JO, Moola S, Weighill T, Scheffler K, Kosakovsky Pond SL. 2012. Detecting individual sites subject to episodic diversifying selection. PLoS Genetics 8:e1002764 DOI: 10.1371/journal.pgen.1002764

Murrell B, Moola S, Mabona A, Weighill T, Sheward D, Kosakovsky Pond SL, Scheffler K. 2013. FUBAR: A fast, unconstrained bayesian AppRoximation for inferring selection. Molecular Biology and Evolution 30: 1196-1205 DOI: 10.1093/molbev/mst030..

Muse S V, Gaut BS. 1994. A likelihood approach for comparing synonymous and nonsynonymous nucleotide substitution rates, with application to the chloroplast genome. Molecular Biology and Evolution 11:715-724 DOI: 10.1093/oxfordjournals.molbev.a040152

Nakajima Y, Mulligan RM. 2001. Heat stress results in incomplete C-to-U edting of maize chloroplast mRNAs and correlates with changes in chloroplast transcription rate. Current Genetics 40: 209-213 DOI: 10.1007/s002940100249

Nguyen L-T, Schmidt HA, von Haeseler A, Minh BQ. 2015. IQ-TREE: A fast and effective stochastic algorithm for estimating Maximum-likelihood phylogenies. Molecular Biology and Evolution 32: 268-274. DOI: 10.1093/molbev/msu300

Nguyen VB, Park H-S, Lee S-C, Lee J, Park JY, Yang T-J. 2017. Authentication markers for five major Panax species developed via comparative analysis of complete chloroplast genome sequences. Journal of Agricultural and Food Chemistry 65:6298-6306. DOI: 10.1021/acs.jafc.7b00925.

Occhialini A, Lin MT, Andralojc PJ, Hanson MR, Parry MAJ. 2016. Transgenic tobacco plants with improved cyanobacterial Rubisco expression but no extra assembly factors grow at near wild-type rates if provided with elevated CO2. Plant Journal 85: 148-160. DOI: 
10.1111/tpj.13098.

847

848

849

850

851

852

853

854

855

856

857

858

859

860

861

862

863

864

865

866

867

868

869

870

871

872

873

Oldenburg DJ, Bendich AJ. 2015. DNA maintenance in plastids and mitochondria of plants. Frontiers in Plant Science 6: 883 DOI: 10.3389/fpls.2015.00883..

Oldenburg DJ, Bendich AJ. 2016. The linear plastid chromosomes of maize: terminal sequences, structures, and implications for DNA replication. Current Genetics 62:431-442. DOI: 10.1007/s00294-015-0548-0.

Olmstead RG, Bohs L. 2007. A summary of molecular systematic research in solanaceae: 19822006. Acta Horticulturae 745: 255-268. DOI: 10.17660/ActaHortic.2007.745.11.

Olmstead RG, Bohs L, Migid HA, Santiago-valentin E. 2008. Molecular phylogeny of the Solanaceae. Molecular Phylogenetics and Evolution 57:1159-1181.

Palmer JD. 1985. Comparative organization of chloroplast genomes. Annual Review of Genetics 19:325-354. DOI: 10.1146/annurev.ge.19.120185.001545.

Pease JB, Haak DC, Hahn MW, Moyle LC. 2016. Phylogenomics reveals three sources of adaptive variation during a rapid radiation. PLoS Biology : e1002379

Peng L, Shikanai T. 2011. Supercomplex formation with photosystem I is required for the stabilization of the chloroplast NADH dehydrogenase-like complex in Arabidopsis. Plant Physiology 155:1629-1639. DOI: 10.1104/pp.110.171264.

Peng L, Yamamoto H, Shikanai T. 2011. Structure and biogenesis of the chloroplast NAD (P) H dehydrogenase complex. Biochimica et Biophysica Acta 1807: 946-953

Picard D, Sempere T, Plantard O. 2008. Direction and timing of uplift propagation in the Peruvian Andes deduced from molecular phylogenetics of highland biotaxa. Earth and Planetary Science Letters 271: 326-336

Piot A, Hackel J, Christin PA, Besnard G. 2018. One-third of the plastid genes evolved under positive selection in PACMAD grasses. Planta 247:255-266. DOI: 10.1007/s00425-0172781-x.

Poczai P, Hyvönen J, Symon DE. 2011. Phylogeny of kangaroo apples (Solanum subg. Archaesolanum, Solanaceae). Molecular Biology Reports 38: 5243-5259 DOI: $10.1007 / \mathrm{s} 11033-011-0675-8$ 
874 Rambaut A, Suchard MA, Xie D, Drummond AJ. 2014. Tracer v1.6. Computer program and 875 documentation distributed by the author, website: http://beast.community/tracer . [accessed 3 $876 \quad$ December 2019]

877

878

879

880

881

882

883

884

885

886

887

888

889

890

891

892

893

894

895

896

897

898

899

900

901

Qian J, Song J, Gao H, Zhu Y, Xu J, Pang X, Yao H, Sun C, Li X, Li C, Liu J, Xu H, Chen S. 2013. The complete chloroplast genome sequence of the medicinal plant Salvia miltiorrhiza. PLoS ONE 8:e57607 DOI: 10.1371/journal.pone.0057607

Ranwez V, Harispe S, Delsuc F, Douzery EJP. 2011. MACSE: multiple alignment of coding SEquences Accounting for frameshifts and stop codons. PLoS One 6: e22594

Ravi V, Khurana JP, Tyagi AK, Khurana P. 2008. An update on chloroplast genomes. Plant Systematics and Evolution 271: 101-122. DOI: 10.1007/s00606-007-0608-0.

Rodrigues NF, Christoff AP, da Fonseca GC, Kulcheski FR, Margis R. 2017. Unveiling chloroplast RNA editing events using next generation small RNA sequencing data. Frontiers in Plant Science 8: 1686. DOI: 10.3389/fpls.2017.01686

Ronquist F. 2004. Bayesian inference of character evolution. Trends in Ecology and Evolution 19: $475-481$

Rozas J, Ferrer-Mata A, Sanchez-DelBarrio JC, Guirao-Rico S, Librado P, Ramos-Onsins SE, Sanchez-Gracia A. 2017. DnaSP 6: DNA sequence polymorphism analysis of large data sets. Molecular Biology and Evolution 34:3299-3302. DOI: 10.1093/molbev/msx248.

Rumeau D, Peltier G, Cournac L. 2007. Chlororespiration and cyclic electron flow around PSI during photosynthesis and plant stress response. Plant, Cell and Environment 30:1041-1051 DOI: $10.1111 / \mathrm{j} .1365-3040.2007 .01675 . x$.

Särkinen T, Bohs L, Olmstead RG, Knapp S. 2013. A phylogenetic framework for evolutionary study of the nightshades (Solanaceae) a dated 1000-tip tree. BMC Evolutionary Biology 13:214

Schiavinato M, Marcet-Houben M, Dohm JC, Gabaldón T, Himmelbauer H. 2020. Parental origin of the allotetraploid tobacco Nicotiana benthamiana. Plant Journal DOI: 10.1111/tpj.14648.

Schiavinato M, Strasser R, Mach L, Dohm JC, Himmelbauer H. 2019. Genome and 
902

903

904

905

906

907

908

909

910

911

912

913

914

915

916

917

918

919

920

921

922

923

924

925

926

927

928

929

930

transcriptome characterization of the glycoengineered Nicotiana benthamiana line $\Delta \mathrm{xT} / \mathrm{FT}$. BMC Genomics 20: 594 DOI: 10.1186/s12864-019-5960-2

Shahzadi I, Abdullah, Mehmood F, Ali Z, Ahmed I, Mirza B. 2019. Chloroplast genome sequences of Artemisia maritima and Artemisia absinthium: Comparative analyses, mutational hotspots in genus Artemisia and phylogeny in family Asteraceae. Genomics 112:1454-1463 DOI: 10.1016/J.YGENO.2019.08.016

Shi L, Chen H, Jiang M, Wang L, Wu X, Huang L, Liu C. 2019. CPGAVAS2, an integrated plastome sequence annotator and analyzer. Nucleic Acids Research 47: W65-W73 DOI: $10.1093 / \mathrm{nar} / \mathrm{gkz} 345$.

Shinozaki K, Ohme M, Tanaka M, Wakasugi T, Hayashida N, Matsubayashi T, Zaita N, Chunwongse J, Obokata J, Yamaguchi-Shinozaki K, Ohto C, Torazawa K, Meng BY, Sugita M, Deno H, Kamogashira T, Yamada K, Kusuda J, Takaiwa F, Kato A, Tohdoh N, Shimada H, Sugiura M. 1986. The complete nucleotide sequence of the tobacco chloroplast genome: its gene organization and expression. The EMBO Journal 5:2043-2049 DOI: 10.1002/j.1460-2075.1986.tb04464.x

Sierro N, Battey JND, Ouadi S, Bakaher N, Bovet L, Willig A, Goepfert S, Peitsch MC, Ivanov NV (2014) The tobacco genome sequence and its comparison with those of tomato and potato. Nature Communications 5:3833

Sierro N, Battey JND, Bovet L, Liedschulte V, Ouadi S, Thomas J, Broye H, Laparra H, Vuarnoz A, Lang G, Goepfert S, Peitsch MC, Ivanov N V. 2018. The impact of genome evolution on the allotetraploid Nicotiana rustica - An intriguing story of enhanced alkaloid production BMC Genomics 19: 855 DOI: 10.1186/s12864-018-5241-5

Simpson, BB. 1975. Pleistocene changes in the Flora of the high tropical Andes. Paleobiology 1: 273-294

Sugiyama Y, Watase Y, Nagase M, Makita N, Yagura S, Hirai A, Sugiura M. 2005. The complete nucleotide sequence and multipartite organization of the tobacco mitochondrial genome: Comparative analysis of mitochondrial genomes in higher plants. Molecular Genetics and Genomics 272:603-615 DOI: 10.1007/s00438-004-1075-8.

Shaw T. 1960. Early Smoking Pipes: In Africa, Europe, and America. The Journal of the Royal 
932

933

934

935

936

937

938

939

940

941

942

943

944

945

946

947

948

949

950

951

952

953

954

955

956

957

958

Terashima I, Araya T, Miyazawa SI, Sone K, Yano S. 2005. Construction and maintenance of the optimal photosynthetic systems of the leaf, herbaceous plant and tree: An ecodevelopmental treatise. Annals of Botany 95:507-519 DOI: 10.1093/aob/mci049.

Tillich M, Lehwark P, Pellizzer T, Ulbricht-Jones ES, Fischer A, Bock R, Greiner S. 2017. GeSeq - versatile and accurate annotation of organelle genomes. Nucleic Acids Research 45:W6-W11. DOI: 10.1093/nar/gkx391.

Winter JC. 2001. Traditional uses of tobacco by native Americans. In: Winter JC (ed) Tobacco use by native North Americans, University of Oklahoma Press, Norman, USA. pp. 57.

Turrill WB, Goodspeed TH. 2007. The Genus Nicotiana. Kew Bulletin 10: 357-358 DOI: $10.2307 / 4109222$.

Xu J-H, Liu Q, Hu W, Wang T, Xue Q, Messing J. 2015. Dynamics of chloroplast genomes in green plants. Genomics 106:221-231. DOI: 10.1016/J.YGENO.2015.07.004.

Xu S, Bröckmöller T, Navarro-Quezada A, Kuhl H, Gase K, Ling Z, Zhou W, Kreitzer C, Stanke M, Tang H, Lyons E, Pandey P, Pandey SP, Timmermann B, Gaquerel E, Baldwin IT. 2017. Wild tobacco genomes reveal the evolution of nicotine biosynthesis. Proceedings of the National Academy of Sciences USA 114:6133-6138

Yamori W. 2016. Photosynthetic response to fluctuating environments and photoprotective strategies under abiotic stress. Journal of Plant Research 129: 379-395 DOI: 10.1007/s10265-016-0816-1.

Yamori W, Shikanai T. 2016. Physiological functions of cyclic electron transport around photosystem I in sustaining photosynthesis and plant growth. Annual Review of Plant Biology 67: 81-106 DOI: 10.1146/annurev-arplant-043015-112002.

Yang Z, Wang G, Ma Q, Ma W, Liang L, Zhao T. 2019. The complete chloroplast genomes of three Betulaceae species: Implications for molecular phylogeny and historical biogeography. PeerJ 7: e6320 DOI: 10.7717/peerj.6320.

Yu Y, Blair C, He XJ. 2020. RASP 4: ancestral state reconstruction tool for multiple genes and characters. Molecular Biology and Evolution 37:604-606. 
959 960

961

962

963

964

965

966

967

968

969

970

971

972

973

974

975

976

977

978

Yukawa M, Tsudzuki T, Sugiura M. 2006. The chloroplast genome of Nicotiana sylvestris and Nicotiana tomentosiformis: Complete sequencing confirms that the Nicotiana sylvestris progenitor is the maternal genome donor of Nicotiana tabacum. Molecular Genetics and Genomics 275:367-373 DOI: 10.1007/s00438-005-0092-6.

\section{Zhang Y, Cui YL, Zhang XL, Yu QB, Wang X, Yuan XB, Qin XM, He XF, Huang C, Yang} ZN. 2018. A nuclear-encoded protein, mTERF6, mediates transcription termination of rpoA polycistron for plastid-encoded RNA polymerase-dependent chloroplast gene expression and chloroplast development. Scientific Reports 8:1-12 DOI: 10.1038/s41598-018-30166-6.

\section{Zhang Y, Du L, Liu A, Chen J, Wu L, Hu W, Zhang W, Kim K, Lee S-C, Yang T-J, Wang} Y. 2016. The Complete Chloroplast Genome Sequences of Five Epimedium Species: Lights into Phylogenetic and Taxonomic Analyses. Frontiers in Plant Science 7:1-12. DOI: 10.3389/fpls.2016.00306. 7, 306 .

Zhang J, Zhang Y, Du Y, Chen S, Tang H. 2011. Dynamic metabonomic responses of tobacco (Nicotiana tabacum) plants to salt stress. Journal of Proteome Research 10:1904-1914 DOI: $10.1021 / \operatorname{pr} 101140$ n.

Zhao Z, Wang X, Yu Y, Yuan S, Jiang D, Zhang Y, Zhang T, Zhong W, Yuan Q, Huang L. 2018. Complete chloroplast genome sequences of Dioscorea: Characterization, genomic resources, and phylogenetic analyses. PeerJ 6:e6032 DOI: 10.7717/peerj.6032. 
979 Figure 1. (a) Chloroplast genome map of five Nicotiana species. Genes lying outside the circle 980 are transcribed clockwise; genes inside the circle are transcribed counterclockwise. Different 981 colors indicate functional groups the genes belong to. GC genome content is plotted light gray and 982 AT dark gray in the inner circle. Large single copy (LSC), inverted repeat A (IRa), inverted repeat $983 \mathrm{~B}(\mathrm{IRb})$ and small single copy (SSC) are shown in the circular diagram. Inverted repeat regions 984 are highlighted with cinderella color. Genes with introns are marked with asterisks. (b) 985 Comparison of amino acid groups and amino acid frequencies in six Nicotiana species. (c) 986 Comparison of the border positions of LSC, SSC and IR among five Nicotiana chloroplast 987 genomes. Positive strand transcribed genes are indicated below the line; negative strand 988 transcribed genes are indicated above the line. Gene names are contained in boxes, and the lengths 989 of relative regions are above the boxes. The number of bp (base pairs) that are written with genes 990 reveal the part of the gene that exists in the region of the chloroplast or away from the region of 991 the chloroplast i.e. bp written with $y c f 1$ indicates that sequences exist in that region of the plastid 992 genome. (d) Maximum likelihood (ML) tree reconstructed from 75 protein-coding plastid genes 993 of 11 Nicotiana species with Solanum dulcamara as an outgroup. Bootstrap support values are 994 shown above or below the nodes.

995 996 997 998 999

1000

1001

1002

1003

1004

1005

1006

1007 1008

Figure 2. Nucleotide diversity of different regions of the chloroplast genome among Nicotiana species. The $\mathrm{x}$-axis indicates the chloroplast regions; $\mathrm{y}$-axis indicates nucleotide diversity.

\section{Figure 3. Plastome phylogeny and biogeography of the tetraploid Nicotiana rustica and} related species. (a) Map showing the six biogeographic areas used to infer the biogeographic history of Nicotiana rustica in South America. Arrows illustrate dispersal events inferred from the biogeographic analysis. Geographical distribution for each terminal is indicated using the biogeographic region's subdivision. The most probable ancestral area is figured at each node of the phylogenetic tree. Pie charts represent relative probabilities of ancestral states at each node. (b) Node-calibrated Bayesian maximum clade credibility tree, with 95\% highest posterior density (HPD) interval for node ages presented as horizontal bars and mean values displayed above each node. All nodes have PP $\geq 0.97$ and $\mathrm{BS} \geq 87 \%$. Trace plot of the combined chains shows the sampled joint probability and the convergence of the chains.

Peer) reviewing PDF | (2020:01:44924:3:0:NEW 15 Jun 2020) 
1009 Table 1. List of amino acid replacements and results of positive selection tests on codons 1010 underlying these replacements.

1011 Table 2. Comparison of substitutions in Nicotiana species.

1012 Table 3. Distribution of indels in the Nicotiana chloroplast genome.

1013 Table 4. Mutational hotspots among Nicotiana species. 


\section{Figure 1}

Chloroplast genome map of five Nicotiana species.

(a) Chloroplast genome map of five Nicotiana species. Genes that lie outside the circle are transcribed clockwise while the genes that transcribed counterclockwise are inside the circle. Different colors indicate the genes belonging to various functional groups. GC and AT content of genome are plotted light grey and dark, respectively, in the inner circle. Large single copy (LSC), inverted repeat A (IRa), inverted repeat B (IRb) and small single copy (SSC) are shown in the circular diagram. Inverted repeat regions are highlighted with cinderella color. Genes

with introns are marked with asterisks. (b) Comparison of amino acid groups and amino acid frequencies in six Nicotiana species. (c) Comparison of the border positions of LSC, SSC and IR among the five Nicotiana chloroplast genomes. Positive strand transcribed genes are indicated under the line while the genes that are transcribed by negative strands are indicated above the line. Gene names are expressed in boxes, and the lengths of relative regions are showed above the boxes. The number of bp (base pairs) that are written with genes reveal the part of the genes that exists in the region of chloroplast or away from region of chloroplast i.e. bp written with ycf1 indicate that sequences exist in that region of the plastid genome. (d) Maximum likelihood (ML) tree was reconstructed based on seventyfive protein coding plastid genes of eleven Nicotiana species and Solanum dulcamara as an outgroup. Bootstrap support values are shown above or below the nodes. 
A

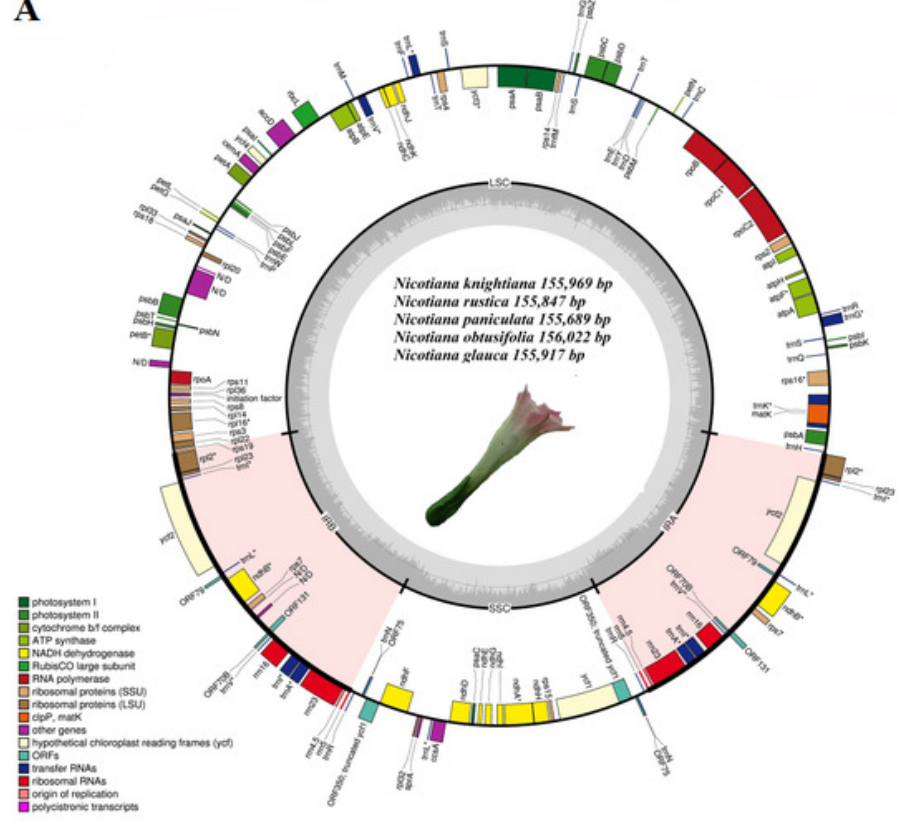

\section{B}

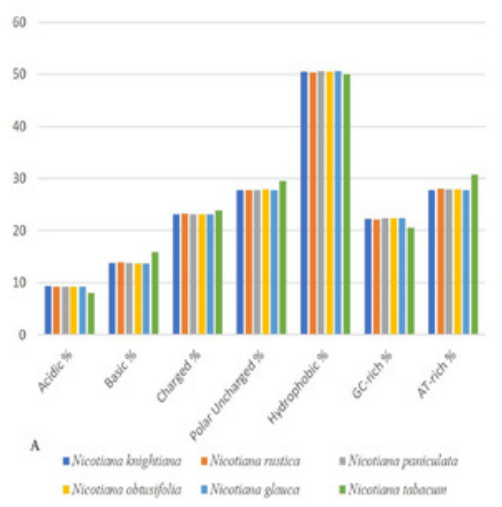

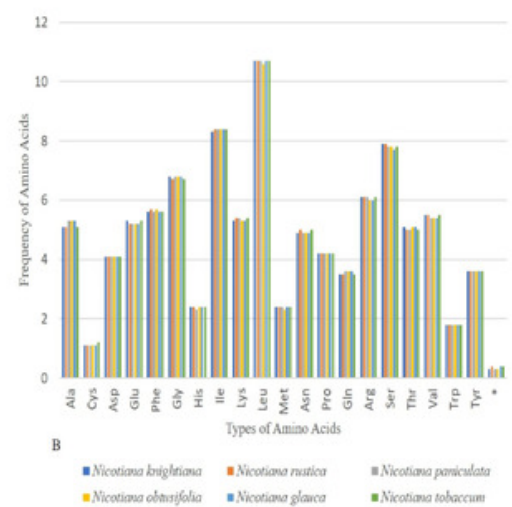

C

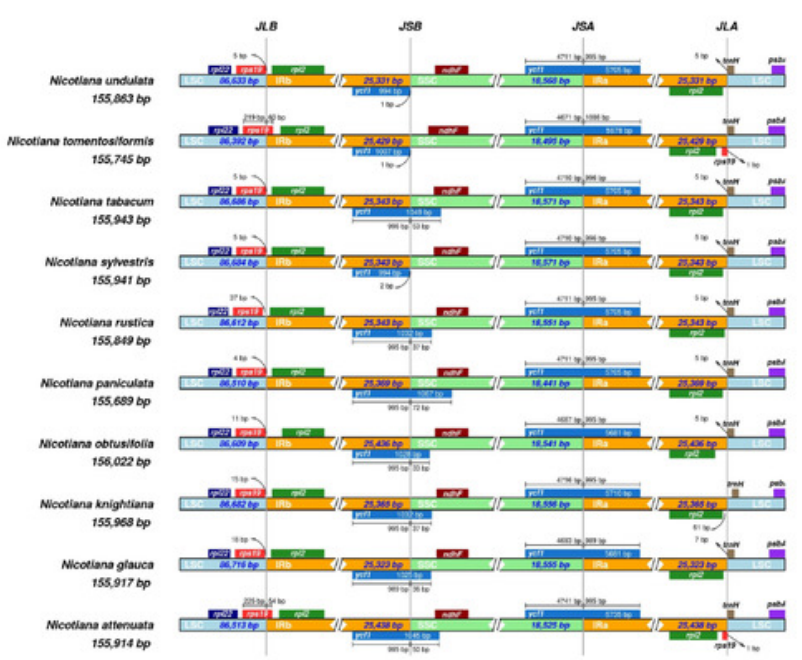

D

Inverted Repeats
- Solanum dulcamara

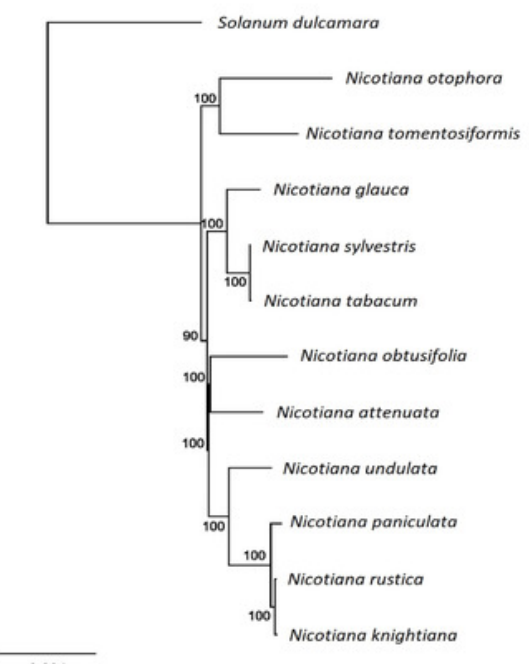


Figure 2

Nucleotide diversity of various regions of the chloroplast genome among Nicotiana species.

The $\mathrm{X}$-axis indicate the chloroplast regions and $\mathrm{Y}$-axis indicate the nucleotide diversity.

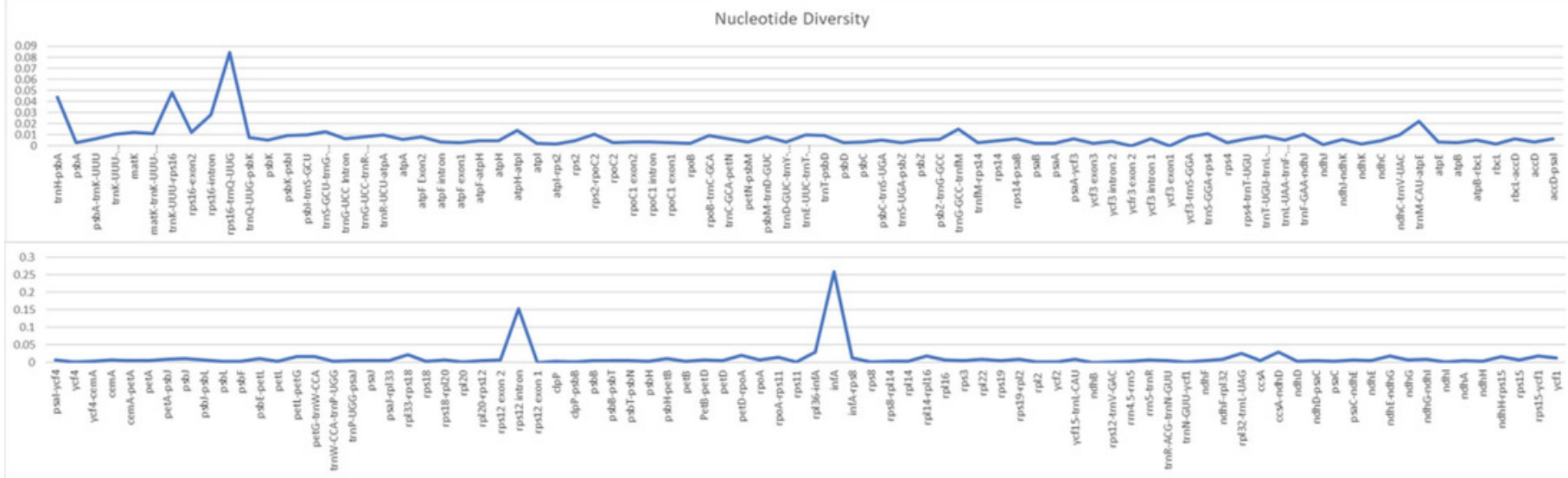




\section{Figure 3}

Plastome phylogeny and biogeography of the tetraploid Nicotiana rustica and related species.

(a) Map showing the six biogeographic areas used to infer the biogeographic history of the Nicotiana rustica in South America. Arrows illustrate the dispersal events inferred from the biogeographic analysis. Geographical distribution for each terminal is indicated using the biogeographic regions subdivision. The most probable ancestral area is figured at each node of the phylogenetic tree. Pie-charts represent relative probabilities of ancestral states at each node. (b) Node-calibrated Bayesian maximum clade credibility tree with $95 \%$ highest posterior density (HPD) interval for node ages presented as horizontal bars and mean values are displayed above each node. All nodes have PP $\geq 0.97$ and BS $\geq 87 \%$. Trace plot of the combined chains showing the sampled joint probability and the convergence of the chains. 
A

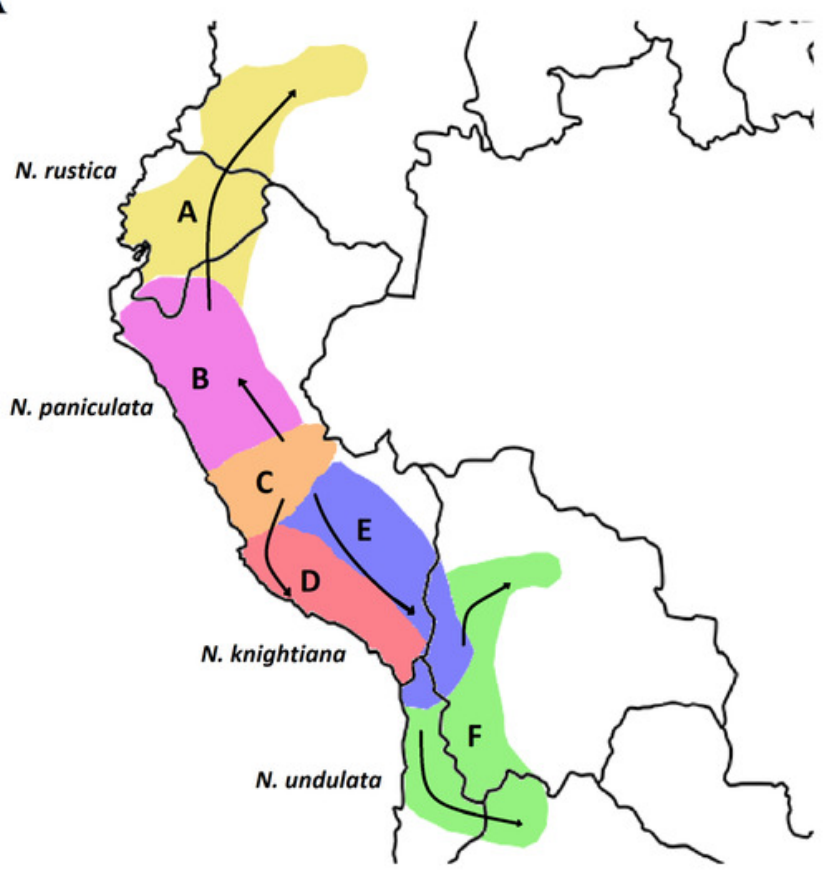

B

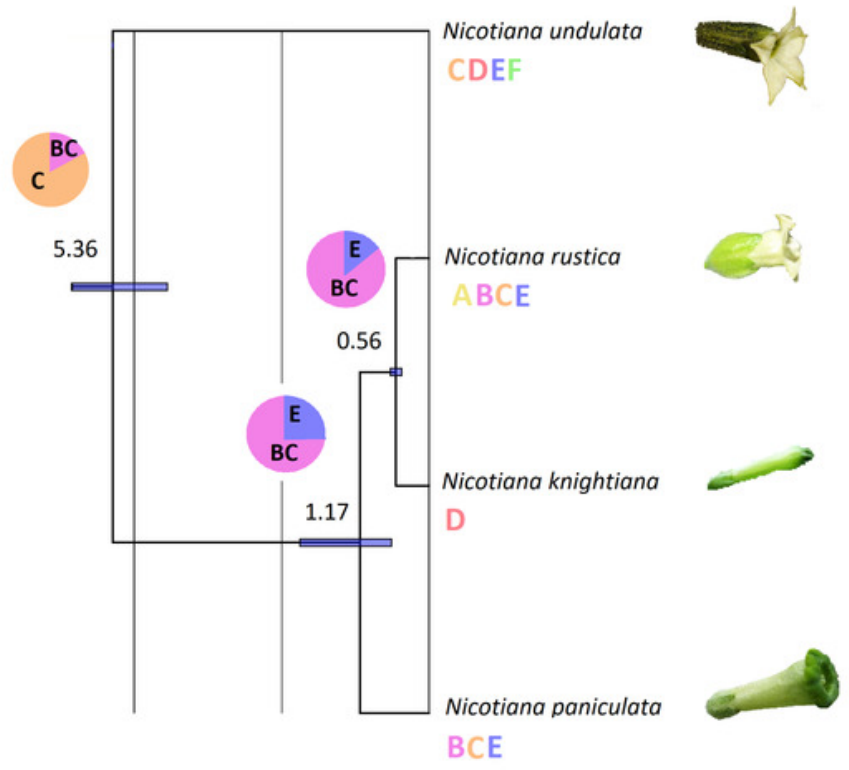




\section{Table 1 (on next page)}

Summary statistics

Summary statistics of de novo assembled Nicotiana plastid genomes 
Table 1. List of amino acid replacements and results of positive selection tests on codons underlying these replacements.

\begin{tabular}{|c|c|c|c|c|c|c|c|c|c|c|c|c|c|c|c|c|c|}
\hline \multirow[t]{2}{*}{ Gene } & \multirow[t]{2}{*}{ Position } & \multirow[t]{2}{*}{$\alpha$} & \multirow[t]{2}{*}{$\boldsymbol{\beta}$} & \multicolumn{11}{|c|}{ Amino acid replacements } & \multirow[t]{2}{*}{$\begin{array}{c}\text { FUBAR } \\
\text { (PP) }\end{array}$} & \multirow[t]{2}{*}{$\begin{array}{c}\text { MEME } \\
\text { (LRT) }\end{array}$} & \multirow[t]{2}{*}{ FDR } \\
\hline & & & & Nat & Ngla & Nkni & Nobt & Noto & Npan & Nrus & Nsyl & Ntab & Ntom & Nund & & & \\
\hline \multirow[t]{2}{*}{$\operatorname{atp} \mathrm{B}$} & 19 & 0.909 & 6.339 & $\mathrm{~K}$ & $\mathrm{~N}$ & $\mathrm{~N}$ & $\mathrm{~K}$ & $\mathrm{~K}$ & $\mathrm{~N}$ & $\mathrm{~N}$ & $\mathrm{~N}$ & $\mathrm{~N}$ & $\mathrm{~N}$ & $\mathrm{~N}$ & 0.918 & 4.42 & 0.044 \\
\hline & 21 & 0.697 & 15.511 & $\mathrm{P}$ & $\mathrm{P}$ & $\mathrm{P}$ & $\mathrm{P}$ & $\mathrm{P}$ & $\mathrm{P}$ & $\mathrm{P}$ & $\mathrm{P}$ & $\mathrm{P}$ & $\mathrm{P}$ & $\mathrm{P}$ & 0.990 & 4.99 & 0.012 \\
\hline \multirow[t]{2}{*}{$n d h \mathrm{D}$} & 153 & 1.981 & 12.245 & $\mathrm{C}$ & $\mathrm{C}$ & $\mathrm{C}$ & $\mathrm{C}$ & $\mathrm{C}$ & $\mathrm{C}$ & $\mathrm{C}$ & $\mathrm{C}$ & $\mathrm{C}$ & $\mathrm{C}$ & $\mathrm{C}$ & 0.927 & 3.16 & 0.021 \\
\hline & 185 & 0.744 & 9.365 & V & $\mathrm{L}$ & V & V & V & V & $\mathrm{V}$ & $\mathrm{L}$ & $\mathrm{L}$ & $\mathrm{V}$ & V & 0.956 & 3.82 & 0.017 \\
\hline$n d h \mathrm{~F}$ & 460 & 1.385 & 8.772 & $\mathrm{~V}$ & V & V & V & $\mathrm{V}$ & V & $\mathrm{V}$ & $\mathrm{A}$ & $\mathrm{A}$ & $\mathrm{V}$ & $\mathrm{V}$ & 0.912 & 3.30 & 0.010 \\
\hline rpoA & 201 & 1.149 & 8.426 & $\mathrm{~L}$ & $\mathrm{~L}$ & $\mathrm{~L}$ & $\mathrm{~L}$ & $\mathrm{~L}$ & $\mathrm{~L}$ & $\mathrm{~L}$ & $\mathrm{~L}$ & $\mathrm{~L}$ & $\mathrm{~L}$ & $\mathrm{~L}$ & 0.940 & 3.84 & 0.023 \\
\hline
\end{tabular}

Note: $\alpha$ - the mean synonymous substitution rate at a site; $\beta$ - the mean non-synonymous substitution rate at a site; PP - posterior

3 probability of positive selection at a site; LRT - Likelihood ratio test for episodic (positive) diversification; FDR - false discovery rate

$4 \quad(\mathrm{FDR}=5 \%)$ Species abbreviations: Nat - N. attenuata; Ngla - N. glauca; Nkni - N. knightiana; Nobt - N. obtusifolia; Noto - N. otophora;

5 Npan - N. paniculata; Nrus - N. rustica; Nsyl - N. sylvestris; Ntab - N. tabacum; Ntom - N. tomentosiformis; Nund - N. undulata. 


\section{Table 2 (on next page)}

Comparison of substitution in Nicotiana species

Comparison of substitution in Nicotiana species. Nicotiana tabacum was used as reference for SNPs detection. 
1 Table 2. Comparison of substitution in Nicotiana species

\begin{tabular}{|c|c|c|c|c|c|}
\hline Types & Nicotiana knightiana & Nicotiana rustica & $\begin{array}{c}\text { Nicotiana } \\
\text { paniculata }\end{array}$ & $\begin{array}{c}\text { Nicotiana } \\
\text { obtusifolia }\end{array}$ & $\begin{array}{c}\text { Nicotiana } \\
\text { glauca }\end{array}$ \\
\hline $\mathrm{A} / \mathrm{G}$ & 222 & 219 & 245 & 244 & 110 \\
\hline $\mathrm{C} / \mathrm{T}$ & 226 & 223 & 237 & 250 & 128 \\
\hline $\mathrm{A} / \mathrm{C}$ & 105 & 104 & 117 & 153 & 97 \\
\hline $\mathrm{C} / \mathrm{G}$ & 40 & 39 & 50 & 52 & 34 \\
\hline $\mathrm{G} / \mathrm{T}$ & 130 & 129 & 135 & 148 & 87 \\
\hline $\mathrm{A} / \mathrm{T}$ & 63 & 61 & 77 & 102 & 53 \\
\hline Total & 786 & 775 & 861 & 847 & 509 \\
\hline \multicolumn{5}{|c|}{ Location wise distribution } \\
\hline LSC & 560 & 559 & 630 & 671 & 327 \\
\hline SSC & 183 & 184 & 198 & 210 & 100 \\
\hline IR & 43 & 32 & 33 & 68 & 82 \\
\hline
\end{tabular}

2

3 Nicotiana tabacum was used as reference for SNPs detection.

4 
Table 3 (on next page)

InDels distribution

InDels distribution of Nicotiana chloroplast genome 
1 Table 3. Distribution of InDels in Nicotiana chloroplast genome

\begin{tabular}{|c|c|c|c|}
\hline & Nicotiana knightiana & InDel length (bp) & InDel average length \\
\hline LSC & 91 & 506 & 5.56 \\
\hline SSC & 11 & 36 & 3.27 \\
\hline IR & 8 & 29 & 3.62 \\
\hline & Nicotiana rustica & InDel length (bp) & InDel average length \\
\hline LSC & 89 & 478 & 5.37 \\
\hline SSC & 11 & 36 & 3.27 \\
\hline IR & 7 & 38 & 5.42 \\
\hline & Nicotiana paniculata & InDel length (bp) & InDel average length \\
\hline LSC & 92 & 618 & 6.71 \\
\hline SSC & 14 & 156 & 11.14 \\
\hline IR & 10 & 28 & 2.80 \\
\hline & Nicotiana obtusifolia & & 5.78 \\
\hline LSC & 117 & 677 & 4.33 \\
\hline SSC & 12 & 52 & 11.92 \\
\hline IR & 14 & 167 & 5.11 \\
\hline & Nicotiana glauca & InDel length (bp) & InDel average length \\
\hline LSC & 88 & 450 & 4 \\
\hline SSC & 11 & 44 & 5.85 \\
\hline IR & 14 & 82 & \\
\hline
\end{tabular}

2 
Table 4 (on next page)

Mutational hotspots

Mutational hotspots among Nicotiana species 
1 Table 4. Mutational hotspots among Nicotiana species

\begin{tabular}{|c|c|c|c|c|}
\hline S. No & Region & $\begin{array}{l}\text { Nucleotide } \\
\text { Diversity }\end{array}$ & $\begin{array}{l}\text { T. No's of } \\
\text { mutation }\end{array}$ & $\begin{array}{l}\text { Region } \\
\text { Length }\end{array}$ \\
\hline 1 & infA & 0.25942 & 45 & 249 \\
\hline 2 & rps 12 intron & 0.15275 & 161 & 527 \\
\hline 3 & rps16-trnQ-UUG & 0.08451 & 225 & 1266 \\
\hline 4 & trnK-UUU-rps 16 & 0.0483 & 46 & 703 \\
\hline 5 & trnH-psbA & 0.04387 & 19 & 433 \\
\hline 6 & rpl36-infA & 0.02942 & 3 & 116 \\
\hline 7 & $\operatorname{ccs} A-n d h D$ & 0.02876 & 17 & 237 \\
\hline 8 & rps16-intron & 0.02784 & 27 & 862 \\
\hline 9 & rpl32-trnL-UAG & 0.02617 & 61 & 931 \\
\hline 10 & trnM-CAU-atpE & 0.02244 & 24 & 218 \\
\hline 11 & rpl33-rps18 & 0.02222 & 20 & 180 \\
\hline 12 & petD-rpoA & 0.01989 & 9 & 182 \\
\hline 13 & rpl14-rpl16 & 0.01849 & 10 & 119 \\
\hline 14 & $n d h E-n d h G$ & 0.01735 & 7 & 219 \\
\hline 15 & $r p s 15-y c f 1$ & 0.01714 & 17 & 385 \\
\hline 16 & ndhH-rps 15 & 0.01667 & 4 & 108 \\
\hline 17 & petG-trnW-CCA & 0.01575 & 4 & 127 \\
\hline 18 & petL-petG & 0.01538 & 6 & 182 \\
\hline 19 & $\operatorname{trn} G-G C C-\operatorname{trn} f M$ & 0.01524 & 11 & 228 \\
\hline 20 & rpoA-rps 11 & 0.01515 & 2 & 66 \\
\hline
\end{tabular}

